\title{
Owning Capital or Being Shareholders: An Equivalence Result with Incomplete Markets*
}

\author{
Eva Carceles Poveda ${ }^{\dagger}$ and Daniele Coen-Pirani ${ }^{\ddagger}$
}

October 8, 2008

\begin{abstract}
Many recent papers in macroeconomics have studied the implications of models with household heterogeneity and incomplete financial markets under the assumption that households own the stock of physical capital and undertake the intertemporal investment decisions. In these models, production exhibits constant returns to scale, households maximize expected discounted utility, and firms rent capital and labor from households to maximize period by period profits. This paper considers the case in which infinitely lived firms, rather than households, make the intertemporal investment decisions. Under this assumption, it shows that there exists an objective function for firms that results in the same equilibrium allocation as in the standard setting with one period lived firms. The objective requires that firms maximize their asset value, which is defined as the discounted value of future cash flows using present value processes that do not allow for arbitrage opportunities.
\end{abstract}

Keywords: Incomplete Markets, Firm Objectives, Value Maximization.

JEL Classification: D52, E44, G12, L20

\section{INTRODUCTION}

Dynamic stochastic general equilibrium models with an infinite horizon and incomplete financial markets have been used extensively in the macroeconomic literature to study a variety of issues (see e.g. Aiyagari (1994) and Krusell and Smith $(1997,1998)$ ). In these models, an homogeneous output good is produced with a constant returns to scale technology that uses capital and labor. Firms rent these two inputs from households to maximize shortrun (period by period) profits, while households own and accumulate the stock of physical capital.

In contrast, the traditional general equilibrium literature with incomplete financial markets (GEI henceforth) models the firm as an infinitely lived entity that owns and accumulates its capital stock and is owned by its shareholders, who trade equity shares in a stock market rather than accumulating physical capital (see Magill and Quinzii, 1996, chapter 6, for a review of this literature). Whereas this provides a more realistic description of the intertemporal behavior of firms, an important result of the GEI literature is that there can be

\footnotetext{
*This paper has been circulated previously under the title "Capital Ownership under Market Incompleteness: Does it matter?". We are very grateful to Michael Magill, Tom Muench, Herakles Polemarchakis, Yair Tauman, and Harald Uhlig for fruitful discussions on the topic. The paper has also benefited from comments of conference participants at the Meetings of the Society for the Advancement in Economic Theory, the NBER Summer Institute, the Econometric Society and the Conference on Computational Economics and Finance, as well as seminar participants at Arizona State, Atlanta Fed, Washington Board of Governors, CEMFI, Duke, Goethe University at Frankfurt, Nova de Lisboa, North Carolina State, Rochester, University of Bilbao and University of Marne la Valle.

${ }^{\dagger}$ Correspondence: Department of Economics, State University of New York, Stony Brook NY-117944384 and IAE-CSIC, Campus UAB, 08193 Bellaterra, Barcelona. Email: ecarcelespov@notes.cc.sunysb.edu. Webpage: http://ms.cc.sunysb.edu/ ecarcelespov/.

${ }^{\ddagger}$ Correspondence: Tepper School of Business, Carnegie Mellon University, Pittsburgh, PA 15217. Email: coenp@andrew.cmu.edu. Webpage: http://www.andrew.cmu.edu/user/coenp/res.htm.
} 
disagreement among shareholders on the path of capital accumulation that the firm should adopt if financial markets are incomplete. This issue has been evaded in the macroeconomic literature by postulating that firms are one period lived entities, in which case the capital accumulation path is well-defined and can be characterized relatively easily.

In this paper we establish a link between these two literatures by showing that the equilibrium allocation in the class of models typically studied in macroeconomics can also be obtained as the equilibrium of a GEI model with a stock market and infinitely-lived firms. A key condition to obtain this result is that the firm objective in the GEI model is "value" maximization. This objective requires that firms discount cash flows with present value processes that are consistent with security prices, in the sense that they satisfy a noarbitrage relation between security prices and their payoffs. An important finding is that the equivalence of allocations in the macroeconomic and the GEI settings holds for any such present value process and for general portfolio restrictions, regardless of whether they are binding or not. Moreover, when borrowing limits are effectively never binding, we show that shareholders unanimously agree on the investment decision of value maximizing firms. ${ }^{1}$

The proof of our result hinges on two properties: that the production function has constant returns to scale in capital and labor and that agents in the economy exhibit uniform impatience. The latter assumption guarantees convergence of present value sums and it rules out stock price bubbles in equilibrium for all present value processes that are consistent with security prices. In the absence of price bubbles, the assumption of constant returns to scale guarantees that the capital stock that is chosen by a value maximizing firm is equal to its stock market value. Given that the stock market value of the firm coincides with the capital stock, a shareholders' choice of how many shares of the firm to hold in the economy with dynamic firms is formally equivalent to a consumer's choice of how many units of capital to accumulate in the economy with static firms. Hence, the equivalence of equilibrium allocations in these two settings.

While our work is related to the GEI literature in multiperiod settings ${ }^{2}$, it relates more closely to the one that assumes value maximization, such as DeMarzo $(1988,1993)$ and Duffie and Shaffer (1986b). The former author demonstrates the validity of the Modigliani-Miller theorem while the latter study the issue of shareholder disagreement and prove existence of equilibria. Differently from these authors, who focus exclusively on firms as intertemporal decision-makers, we study the relationship between the allocations obtained in settings in which firms accumulate physical capital and the allocations obtained in the standard macroeconomic setting in which firms rent the physical capital and solve static decision problems.

The rest of the paper is organized as follows. The following section introduces the model and Section 3 presents the main equivalence results. These are further discussed in Section 4. Section 5 summarizes and concludes.

\section{The Model Economies}

In this section, we first introduce a common general environment and then present the two different model economies. The first economy is the one typically considered in the macroeconomic literature, where households own the stock of physical capital and make

\footnotetext{
${ }^{1}$ Carceles-Poveda and Coen-Pirani (2008) discuss the issue of shareholder disagreement in a similar context with two periods. Apart from the fact that they focus on the preferences of shareholders with respect to the investment decision of the firm, the present paper generalizes that model in two important directions. First, we allow for the possibility of binding borrowing constraints. Second, we consider an infinite horizon economy. In the latter, asset prices can in principle deviate from their fundamental values and this possibility has to be explicitly ruled out in order to establish our main equivalence result.

${ }^{2}$ See e.g. Hernandez and Santos (1996), Levine (1989), Magill and Quinzii (1994a,1994b), and Levine and Zame (1996), who have established the existence of an equilibrium in multiperiod economies with incomplete markets.
} 
intertemporal investment decisions, whereas the representative firm simply rents capital and labor from the households to maximize profits on a period by period basis. In this sense, the firm can be considered as being static or short lived. Second, we consider the case in which the firm is the owner of the stock of physical capital. Here, the firm is dynamic and is assumed to undertake all the intertemporal investment decisions.

2.1. The General Environment. We consider an infinite horizon economy with aggregate uncertainty, idiosyncratic income shocks and sequential trading. The economy is populated by a representative firm and a finite set $I$ of infinitely lived households that are indexed by $i .^{3}$ Time is discrete and indexed by $t=\{0,1,2 \ldots\}$ and the set of states of nature is denoted by $S$. The revelation of information is described by a sequence of partitions of $S$, denoted by $\digamma=\left(\digamma_{0}, \digamma_{1}, \ldots, \digamma_{t}, \ldots\right)$, where the number of subsets in $\digamma$ is finite. Since there is no information at date $0, \digamma_{0}=S$. Further, the information available to agents at time $t$ is described by the subset $\sigma$ of $\digamma_{t}$ in which the state of nature lies. A pair $\xi=(t, \sigma)$ with $\sigma \in \digamma_{t}$ is called a date-event or node and $t(\xi)$ is the date of node $\xi$. The set $D=\cup(t, \sigma)$ for all $t$ and $\sigma \in \digamma_{t}$ consisting of all date-events is the event tree induced by $\digamma$.

We say that a node $\xi^{\prime}=\left(t^{\prime}, \sigma^{\prime}\right)$ succeeds (strictly) node $\xi=(t, \sigma)$ if $t^{\prime} \geq t\left(t^{\prime}>t\right)$ and $\sigma^{\prime} \subset \sigma$. In this case, we write $\xi^{\prime} \geq \xi\left(\xi^{\prime}>\xi\right)$. The set of nodes that succeeds a node $\xi$ is called $D(\xi)$ and the set of strict successors of $\xi$ is called $D^{+}(\xi)=\left\{\xi^{\prime} \in D(\xi) \mid \xi^{\prime}>\xi\right\}$. The set of immediate successors of $\xi$ is denoted by $\xi^{+}=\left\{\xi^{\prime} \in D(\xi) \mid t^{\prime}=t+1\right\}$. The number of elements of $\xi^{+}$is finite and is called the branching number $b(\xi)$. If $\xi=(t, \sigma)$ with $t \geq 1$, then the unique node $\xi^{-}=\left(t-1, \sigma^{\prime}\right)$ with $\sigma \subset \sigma^{\prime}$ is the predecessor of $\xi$. The probability of date-event $\xi$ is denoted by $\pi(\xi)$, with $\pi\left(\xi_{0}\right)=1$. Throughout the text, $x^{T}$ denotes the transpose of $x$.

Technology. At each node $\xi \in D$, the single consumption good $y(\xi) \in \mathbb{R}_{+}$is produced with the aggregate technology:

$$
y(\xi)=f\left(z(\xi), k\left(\xi^{-}\right), n(\xi)\right)
$$

where $k\left(\xi^{-}\right) \in \mathbb{R}_{+}$and $n(\xi) \in \mathbb{R}_{+}$denote the aggregate physical capital and labor, $z(\xi)$ is an aggregate productivity shock, and the initial stock of capital, denoted by $k\left(\xi_{-1}\right) \in \mathbb{R}_{++}$, is given. We make the following assumptions.

(A.1) The technology shock follows a (Markov) process with state space $S_{z}$, where $S_{z}=$ $\left\{z_{m}: m \in M_{z}, z_{m} \in[\underline{z}, \bar{z}]\right\}, M_{z}$ is a finite set of integers, $0<\underline{z}<\bar{z}<+\infty$, and the initial realization $z\left(\xi_{0}\right)$ is given.

(A.2) Given $z$, the production function $f(z, \cdot, \cdot): \mathbb{R}_{+}^{2} \rightarrow \mathbb{R}_{+}$is continuously differentiable on the interior of its domain, strictly increasing, strictly quasiconcave, and homogeneous of degree one in the two arguments. We also assume that $f(z, 0, n)=0, f_{k}(z, k, n)>$ 0 and $f_{n}(z, k, n)>0$ for all $k>0$ and $n>0$. Further, $\lim _{k \rightarrow 0} f_{k}(z, k, n)=\infty$ and $\lim _{k \rightarrow \infty} f_{k}(z, k, n)=0$ for all $n>0$.

The previous two assumptions are standard in the macroeconomic literature. Assumption (A.1) models the technology shock as a stationary Markov chain. It is important to note that our results only require that the shock takes a finite number of positive values, and we can therefore relax the Markov assumption. Further, assumption (A.2) imposes standard conditions on the production process. In particular, the homogeneity assumption implies

\footnotetext{
${ }^{3}$ For convenience of notation we consider the case of a finite number of agents. However, all the results in the paper also apply when there is a continuum of agents. Moreover, whereas the analysis assumes the existence of a representative firm (or a large number of identical firms) and no external financing of the investment level, our results can also be extended to the cases where firms are heterogeneous and where investment is financed with external funds. We discuss these issues in Section 4.
} 
that $f(z, k, n)=f_{k}(z, k, n) k+f_{n}(z, k, n) n$ via Euler's theorem. As we will see later, this last property is crucial to obtain our results.

The aggregate capital stock depreciates at the rate $\delta \in(0,1)$, and we denote the total supply of goods available from production at $\xi$ including undepreciated capital by:

$$
F\left(z(\xi), k\left(\xi^{-}\right), n(\xi)\right)=f\left(z(\xi), k\left(\xi^{-}\right), n(\xi)\right)+(1-\delta) k\left(\xi^{-}\right) .
$$

Financial Markets. At each date-event, there exist financial markets for a finite number $J$ of securities. The first is a claim to productive activity that is indexed by $j=1$. The rest are financial assets whose returns are denominated in units of the consumption good.

A security $j \in J$ traded at node $\xi$ is defined by its current price $q^{j}(\xi) \in \mathbb{R}_{+}$ex-dividend (after the dividend at $\xi$ has been paid) and by the payoffs it promises to deliver at future nodes. If household $i \in I$ purchases a portfolio of securities $a_{i}(\xi)=\left(a^{j}(\xi), j \in J\right) \in \mathbb{R}^{J}$ at period $t$, he is entitled to a one period payoff of $R\left(\xi^{\prime}\right)^{T}=\left[d\left(\xi^{\prime}\right)+q\left(\xi^{\prime}\right)^{T}\right]$ if date-event $\xi^{\prime} \in \xi^{+}$ is realized, where $q(\xi)=\left(q^{j}(\xi), j \in J\right)^{T}$ and $d(\xi)=\left(d^{j}(\xi), j \in J\right)$ are the vectors of prices and dividends respectively. ${ }^{4}$ In what follows, we denote the price and the portfolio process of agent $i \in I$ by $q=(q(\xi), \xi \in D) \in \mathbb{R}^{D \times J}$ and $a_{i}=\left(a_{i}(\xi), \xi \in D\right) \in \mathbb{R}^{D \times J}$ respectively.

A security traded at $\xi$ is of finite maturity if there exists a node (after its node of issue) beyond which it makes no payment, namely, $\xi^{\prime} \in D(\xi)$ is a maturity node if $R^{j}\left(\xi^{\prime}\right)=0$ for all $\xi^{\prime}>\xi$. Otherwise, the security is infinitely lived. Further, security markets are one period complete at node $\xi$ if the rank of the return matrix $\left[R\left(\xi^{\prime}\right)^{T}\right]_{\xi^{\prime} \in \xi^{+}}$is equal to $b(\xi)$. Markets are complete if they are one period complete at every date-state. We make the following assumption.

(A.3) For all $\xi \in D, d(\xi) \in \mathbb{R}_{+}$and there exists some $\varepsilon>0$ such that $d^{1}(\xi) \geq \varepsilon$.

Assumption (A.3) requires that dividends are nonnegative. This is consistent with the fact that free disposal of securities implies nonnegative security prices. In addition, it imposes the additional restriction that dividends on the productive claim are bounded away from zero at each node. As we will show later, this rules out stock price bubbles in equilibrium. ${ }^{5}$

All the results in the paper hold whether markets are complete or incomplete. Clearly, a necessary condition for markets to be complete is that $J \geq b(\xi)$ at all $\xi \in D$. However, we are particularly interested in the case where markets are incomplete, namely, $J \leq b(\xi)$ at all $\xi \in D$.

No Arbitrage Pricing. The security price process $q$ is arbitrage free at $\xi$ if there does not exist a portfolio $a(\xi) \in \mathbb{R}^{J}$ such that $R\left(\xi^{\prime}\right)^{T} a(\xi) \geq 0$ for all $\xi^{\prime} \in \xi^{+}$and $q(\xi)^{T} a(\xi) \leq 0$, with at least one strict inequality. In other words, arbitrage free prices have to be such that it is not possible to construct a portfolio with non-positive value and nonnegative payoffs at every successor node. While this must be the case in equilibrium, the presence of no-arbitrage at date-state $\xi$ implies the existence of a process $\lambda=(\lambda(\xi), \xi \in D)$ of positive no-arbitrage (NA) present value prices such that, for all $\xi \in D$ :

$$
q(\xi)^{T}=\sum_{\xi^{\prime} \in \xi^{+}} \frac{\lambda\left(\xi^{\prime}\right)}{\lambda(\xi)} R\left(\xi^{\prime}\right)^{T}
$$

\footnotetext{
${ }^{4}$ For simplicity, we abstract from securities that pay bundles of other securities and from trade in different securities at different date-states, although this can be easily incorporated at the expense of additional notation. See Magill and Quinzii (1994), Santos and Woodford (1997) or Hernandez and Santos (1996).

${ }^{5}$ Since the dividends on the productive claim are positive in a neighbourhood of the non stochastic steady state, one can actually impose restrictions on the process of the exogenous technology shock and on the initial capital stock $k\left(s^{-1}\right)$ such that the restriction on $d_{1}\left(s^{t}\right)$ is satisfied at each node. For example, one could assume that the variance of the exogenous technology shock is sufficiently small, while the initial capital is sufficiently close to the steady state value.
} 
Given $(q, d)$, the absence of arbitrage at each date-state $\xi$ allows us to define processes $\lambda$ for the entire information structure such that the previous no-arbitrage equation holds. In what follows, we denote the set of such processes for the sub-tree with root $\xi$ by $Q_{\xi}(q, d)$. Note that the present value ratios $\lambda\left(\xi^{\prime}\right) / \lambda(\xi)$ that are consistent with security prices are uniquely determined by (3) if markets are complete. On the other hand, the number of linearly independent equations is not sufficient to uniquely determine the ratios when markets are incomplete.

The previous NA present value prices can be used to evaluate future streams of consumption goods. In particular, for a non-negative resource stream $x$ with $x(\xi) \in \mathbb{R}_{+}$for all $\xi \in D$, the present value at $\xi$ of the subsequent stream with respect to some NA present value price $\lambda \in Q_{\xi}(q, d)$ can be defined as:

$$
v_{x}(\xi, \lambda)=\sum_{\xi^{\prime} \in D^{+}(\xi)} \frac{\lambda\left(\xi^{\prime}\right)}{\lambda(\xi)} x\left(\xi^{\prime}\right)
$$

Note that this sum may diverge, in which case we say that $v_{x}(\xi, \lambda)=+\infty$. Using NA present value prices, we can also define the fundamental value $v_{d^{j}}(\xi, \lambda)$ of security $j \in J$ with respect to some $\lambda \in Q_{\xi}(q, d)$. In addition, using some algebra, the bubble component of the security with respect to $\lambda \in Q_{\xi}(q, d)$ can be expressed as:

$$
\sigma^{j}(\xi, \lambda)=q^{j}(\xi)-v_{d^{j}}(\xi, \lambda)=\lim _{\widetilde{T} \rightarrow \infty} \sum_{\xi^{\prime} \in D(\xi), t\left(\xi^{\prime}\right)=\widetilde{T}} \frac{\lambda\left(\xi^{\prime}\right)}{\lambda(\xi)} q^{j}\left(\xi^{\prime}\right)
$$

As shown by Santos and Woodford (1997), if a security price is non-negative, its fundamental value $v_{d^{j}}(\xi, \lambda)$ satisfies $0 \leq v_{d^{j}}(\xi, \lambda) \leq q^{j}(\xi)$ for all $\lambda \in Q_{\xi}(q, d)$. Further, whereas the fundamental value need not be the same for all state prices satisfying equation (3), the authors show that it must lie between the finite bounds ${ }^{6} \underline{v}_{d^{j}}(\xi, \lambda)=\inf _{\lambda \in Q_{\xi}(q, d)} v_{d^{j}}(\xi, \lambda)$ and $\bar{v}_{d^{j}}(\xi, \lambda)=\sup _{\lambda \in Q_{\xi}(q, d)} v_{d^{j}}(\xi, \lambda)$. Clearly, there exists no bubble for security $j \in J$ if $\underline{v}_{d^{j}}(\xi, \lambda)=\bar{v}_{d^{j}}(\xi, \lambda)=q^{j}(\xi)$. In this case, the fundamental value is uniquely defined for all $\lambda \in Q_{\xi}(q, d)$. This observation will be useful later on.

Households. Households' preferences $\succsim=\left(\succsim_{i}, i \in I\right)$ over consumption plans $c_{i}$ satisfy the following assumption.

(A.4) For every $i \in I, \succsim_{i}$ can be represented by the following function:

$$
U_{i}\left(c_{i}\right)=\sum_{\xi \in D} \beta_{i}^{t(\xi)} \pi(\xi) u_{i}\left(c_{i}(\xi)\right)
$$

where $\beta_{i} \in(0,1)$ is the individual discount factor, and the period utility function $u_{i}: \mathbb{R}_{+} \rightarrow \mathbb{R}$ is strictly increasing, strictly concave and continuously differentiable in the interior of its domain, with $\lim _{c_{i} \rightarrow 0} u_{i}^{\prime}\left(c_{i}\right)=\infty$ and $\lim _{c_{i} \rightarrow \infty} u_{i}^{\prime}\left(c_{i}\right)=0$.

The class of preferences in assumption (A.4) is standard in the macroeconomic literature. It is important to note that this class of preferences satisfies the property that there is a "uniform lower bound on the impatience" of each agent. This last property, which is stated formally in the appendix, has been assumed by several authors studying infinite horizon exchange economies with incomplete markets, such as Santos and Woodford (1997), Magill and Quinzii (1994a,1994b), Hernandez and Santos (1996) and Levine and Zame (1996). In essence, it requires that at each node $\xi$ an agent is willing to give up a fraction of his future

\footnotetext{
${ }^{6}$ These results follow from Propositions 2.1 and 2.2 in Santos and Woodford (1997), which can be directly applied to our setup.
} 
consumption after node $\xi$ in exchange for a multiple of the current aggregate endowment. Further, the fraction of future consumption that each agent is willing to give up (or the degree of impatience), is uniform across all nodes and feasible consumption plans. As we will see later, this property is crucial to establish the absence of price bubbles in the present setup.

Each household $i \in I$ enters the markets at $t=0$ with a finite initial endowment $a_{i}^{j}\left(\xi_{-1}\right)$ of each security, whose sum across households determines the net supply of the security at each node, which we denote by $A^{j}=\sum_{i \in I} a_{i}^{j}\left(\xi_{-1}\right)$. Without loss of generality, the supply of the productive claim and of the rest of securities is normalized to one and zero respectively, and we let $A=\left(A^{1}, \ldots, A^{J}\right)^{\prime}$. At each date-state $\xi \in D$, households are also endowed with one unit of time that is entirely allocated to labor, and which they can transform into $\epsilon_{i}(\xi)$ efficiency labor units that will be used to produce output in exchange of wages. Given this, the labor income of the household at $\xi$ is given by $w_{i}(\xi)=w(\xi) \epsilon_{i}(\xi)$, where $w(\xi)$ is the fraction of output allocated to labor payments. We make the following assumptions.

(A.5) For all $i \in I, a_{i}\left(\xi_{-1}\right) \in \mathbb{R}_{+}$.

(A.6) The labor income shock $\epsilon_{i}$ follows a (Markov) process with state space $S_{\epsilon}$, where $S_{\epsilon}=\left\{\epsilon_{i m}: m \in M_{\epsilon}, \epsilon_{i m} \in[\underline{\epsilon}, \bar{\epsilon}]\right\}, M_{\epsilon}$ is a finite set of integers, $0<\underline{\epsilon}<\bar{\epsilon}<1$, and the initial realization $\epsilon_{i}\left(\xi_{0}\right)$ is given.

Assumption (A.5) guarantees that the supply of each security is non-negative. Further, assumption (A.6) models the labor income shock as a discrete state Markov chain. As before, our results only require that the shock takes a finite number of positive values, and we can therefore relax the Markov assumption. The aggregate and idiosyncratic shocks could potentially be correlated, and we denote their joint transition matrix by $\Pi$ in what follows.

At each node $\xi$, household $i \in I$ chooses consumption $c_{i}(\xi) \in \mathbb{R}_{+}$and a portfolio of securities $a_{i}(\xi) \in \mathbb{R}^{J}$ subject to the following constraints:

$$
\begin{gathered}
c_{i}(\xi)+q(\xi)^{T} a_{i}(\xi) \leq \omega_{i}(\xi) \\
\omega_{i}\left(\xi^{\prime}\right)=w_{i}\left(\xi^{\prime}\right)+R\left(\xi^{\prime}\right)^{T} a_{i}(\xi) \text { for } \xi^{\prime} \in \xi^{+} \\
q(\xi)^{T} a_{i}(\xi) \geq B_{i}(\xi) .
\end{gathered}
$$

Equation (5) is the standard budget constraint with sequential markets and equation (6) is the law of motion of the individual wealth $\omega_{i}(\xi)$. At $t=0$, equation (6) takes the same form with $\omega_{i}\left(\xi_{0}\right)=q\left(\xi_{0}\right)^{T} a_{i}\left(\xi_{-1}\right)+d^{1}\left(\xi_{0}\right) a_{i}^{1}\left(\xi_{-1}\right)+w_{i}\left(\xi_{0}\right)$, where we have used the fact that $d^{j}\left(\xi_{0}\right)=0$ for $j \geq 2$. Finally, to avoid Ponzi schemes, equation (7) imposes a finite limit of $B_{i}(\xi)$ on the total amount that households can borrow at every node. ${ }^{7}$

A possible trading restriction that one can impose is the present value borrowing constraint, which is never binding at any finite date. This is defined as the tightest borrowing limit such that the portfolio holdings satisfy the budget constraint with $c_{i}(\xi) \in \mathbb{R}_{+}$for all $\xi \in D$, and wealth is always non-negative after a finite date. As shown by Santos and Woodford (1997), this constraint can be specified formally as:

$$
B_{i}(\xi)=-\underline{v}_{w_{i}}(\xi, \lambda) \text { where } \underline{v}_{w_{i}}(\xi, \lambda)=\inf _{\lambda \in Q_{\xi}(q, d)} v_{w_{i}}(\xi, \lambda)
$$

In essence, the restriction implies that households can borrow at most the lowest present value of their individual endowments in order to be solvent. The two production economies are described in what follows.

\footnotetext{
${ }^{7}$ Alternatively, one could impose constraints on the individual asset holdings, since market clearing implies that in every asset market and every node there exists at least one household that is unconstrained.
} 
2.2. The $k$-Economy. In the $k$-economy, we make the usual assumption in the macroeconomic literature, implying that households are the owners of the physical capital stock and make the intertemporal investment decision. In this case, the problem of the firm is particularly simple. At each date-state $\xi$, after observing the realization of the productivity shock $z$, the firm chooses capital and labor to maximize period profits. Thus, it solves a sequence of static problems:

$$
\operatorname{Max}_{\{k, n\}}\left[F\left(z(\xi), k\left(\xi^{-}\right), n(\xi)\right)-w(\xi) n(\xi)-r(\xi) k\left(\xi^{-}\right)\right]
$$

leading to the following necessary and sufficient first order conditions:

$$
\begin{gathered}
w(\xi)=F_{n}\left(z(\xi), k\left(\xi^{-}\right), n(\xi)\right)=f_{n}\left(z(\xi), k\left(\xi^{-}\right), n(\xi)\right) \\
r(\xi)=F_{k}\left(z(\xi), k\left(\xi^{-}\right), n(\xi)\right)=f_{k}\left(z(\xi), k\left(\xi^{-}\right), n(\xi)\right)+1-\delta
\end{gathered}
$$

where $w(\xi) \in \mathbb{R}_{+}$and $r(\xi) \in \mathbb{R}_{+}$are the competitively determined wage and gross capital rental rates respectively. Further, each household $i \in I$ maximizes the preferences in (A.5) subject to the following constraints:

$$
\begin{gathered}
c_{i}(\xi)+k_{i}(\xi)+\sum_{j \geq 2} q^{j}(\xi) a_{i}^{j}(\xi) \leq \omega_{i}(\xi) \\
\omega_{i}\left(\xi^{\prime}\right)=w_{i}\left(\xi^{\prime}\right)+r\left(\xi^{\prime}\right) k_{i}(\xi)+\sum_{j \geq 2} R^{j}\left(\xi^{\prime}\right) a_{i}^{j}(\xi) \text { for } \xi^{\prime} \in \xi^{+} \\
k_{i}(\xi)+\sum_{j \geq 2} q^{j}(\xi) a_{i}^{j}(\xi) \geq B_{i}(\xi)
\end{gathered}
$$

In the previous equations, $k_{i}(\xi)$ is the amount of physical capital held by the household at the end of period $t$, illustrating the fact that households make the intertemporal investment decision. If we denote by $k_{i}\left(\xi_{-1}\right)$ and $a_{i}\left(\xi_{-1}\right)$ the initial asset holdings of $i$ at $t=0$, the period zero budget constraint takes the same form with $\omega_{i}\left(\xi_{0}\right)=w_{i}\left(\xi_{0}\right)+r\left(\xi_{0}\right) k_{i}\left(\xi_{-1}\right)+q\left(\xi_{0}\right) a_{i}\left(\xi_{-1}\right)$.

A $k$-economy is specified by a set of preferences $\succsim$, a transition matrix $\Pi$, initial values $\left(k_{0}, a_{0}, z_{0}, \epsilon_{0}\right)=\left\{k\left(\xi_{-1}\right),\left(a_{i}\left(\xi_{-1}\right), \epsilon_{i}\left(\xi_{0}\right)\right)_{i \in I}, z\left(\xi_{0}\right)\right\}$, security processes $d^{a}=\left(d^{j}\right)_{j \geq 2}$ and borrowing limits $B=\left(B_{i}\right)_{i \in I}$, where $a_{i}^{1}\left(\xi_{-1}\right)=k_{i}\left(\xi_{-1}\right) / k\left(\xi_{-1}\right)$ represents the initial endowment of capital shares of household $i \in I$. A $k$-economy is therefore described by $E_{k}=\left\{\succsim,\left(k_{0}, a_{0}, z_{0}, \epsilon_{0}\right), \Pi, d^{a}, B\right\}$.

Definition 2.1. The vector of processes $\left\{\left(c_{i}, k_{i},\left(a_{i}^{j}\right)_{j \geq 2}\right)_{i \in I},\left(q^{j}\right)_{j \geq 2},(w, r)\right\}$ is a competitive equilibrium $(\mathrm{CE})$ for $E_{k}$ if:

(i) For each $i \in I$ and for each $\xi \in D,\left\{c_{i}, k_{i},\left(a_{i}^{j}\right)_{j \geq 2}\right\}$ is optimal under the preferences $\succsim$ given $\left(q^{j}\right)_{j \geq 2},(w, r),\left(k_{0}, a_{0}, z_{0}, \epsilon_{0}\right), \Pi, d^{a}$ and $B$.

(ii) $(w, r)$ satisfies the firm's optimality conditions.

(iii) All markets clear, i.e., for all $\xi \in D, n(\xi)=\sum_{i \in I} \epsilon_{i}(\xi), \sum_{i \in I} k_{i}(\xi)=k(\xi), \sum_{i \in I} a_{i}^{j}(\xi)=$ $A^{j}$ for $j \geq 2$ and $\sum_{i \in I} c_{i}(\xi)=w_{c}(\xi)=w(\xi) n(\xi)+d(\xi) A$.

Before discussing the framework with dynamic firms, it is important to note that the constraints faced by the household sector in the $k$-economy can be directly mapped into the framework of the general environment if we define the shares of physical capital held by household $i$ at date-state $\xi$ as $a_{i}^{1}(\xi)=k_{i}(\xi) / k(\xi)$. With this normalization, the total supply of shares is positive and equal to $A^{1}=1$. Further, $q^{1}(\xi)=k(\xi), R^{1}(\xi)=r(\xi) k\left(\xi^{-}\right)$and $d^{1}(\xi)=r(\xi) k\left(\xi^{-}\right)-k(\xi)=F\left(z(\xi), k\left(\xi^{-}\right), n(\xi)\right)-w(\xi) n(\xi)-k(\xi)$. 
2.3. The $e$-Economy. In the $e$-economy, we assume that the firm owns the entire stock of capital and undertakes the intertemporal investment decision by solving a dynamic optimization problem. Further, households are entitled to the future dividend payments through their ownership of a perfectly divisible equity share in the firm that is traded at price $q^{1}(\xi)$.

At each node $\xi$, households maximize the preferences in (A.5) subject to constraints (5)(7). Further, the firm produces output, pays wages to the total labor employed and decides on the amount of investment. Investment is entirely financed with retained earnings, and the residual of gross profits (output net of labor payments) and investment is paid out as dividends to the firm equity owners, i.e.,

$$
d^{1}(\xi)=F\left(z(\xi), k\left(\xi^{-}\right), n(\xi)\right)-w(\xi) n(\xi)-k(\xi)
$$

where $d^{1}(\xi)$ is the net cash flow of the firm. Unfortunately, the definition of an appropriate firm objective is more complicated than before, since the standard approach, that firms maximize their share value, is not well-specified under market incompleteness. The reason is that the available markets do not provide sufficient information to value future dividend streams unambiguously. To see this, consider the case of effective complete markets and let $\frac{\lambda\left(\xi^{\prime}\right)}{\lambda(\xi)}=\frac{\lambda_{i}\left(\xi^{\prime}\right)}{\lambda_{i}(\xi)}$ for $i \in I$ and $\xi^{\prime} \in D_{t+r}(\xi)$ be the $t+r$-period ahead pricing kernel. Note that this pricing kernel represents the period $t$ price of one unit of time $t+r$ consumption, contingent on the economy being at date-state $\xi^{\prime} \in D_{t+r}(\xi)$. Since all the shareholders will agree on the pricing kernel under complete markets, the objective of the firm at date-state $\xi$ can then be naturally specified as follows:

$$
\operatorname{Max}_{\{k, n\}} \sum_{\xi^{\prime} \in D^{+}(\xi)} \frac{\lambda\left(\xi^{\prime}\right)}{\lambda(\xi)} d^{1}\left(\xi^{\prime}\right) \text { where } \lambda(\xi)=\beta_{i}^{t(\xi)} \pi(\xi) u_{i}^{\prime}\left(c_{i}(\xi)\right) \text { for all } i \in I
$$

When markets are complete, the firm maximizes the present discounted value of its net cash flows, using as a discount factor the unique present value process of its shareholders, which is also the only element of the set $Q_{\xi}(q, d)$. In addition, both the agents and the firm value future output in each state identically, and all shareholders will therefore agree with the investment choice made by the firm. On the other hand, since a unique present value process that is consistent with market prices is not necessarily available under market incompleteness, the previous objective is no longer well-defined, and shareholder disagreement may result in equilibrium. ${ }^{8}$

Value Maximization. In this paper we focus on the objective of value maximization. ${ }^{9}$ As noted by DeMarzo (1993), a natural generalization of the previous Arrow Debreu firm objective to an incomplete markets setup is to require firms to maximize the value of their output according to some consistent present value prices, in the sense that they satisfy the no-arbitrage condition in (3). The two-period value maximizing firm objective postulated by this author can be expressed in our multiperiod setup as follows:

$$
U_{f}\left(d^{1}\right)=\operatorname{Max}_{\{k, n\}} \sum_{\xi^{\prime} \in D^{+}(\xi)} \frac{\lambda\left(\xi^{\prime}\right)}{\lambda(\xi)} d^{1}\left(\xi^{\prime}\right) \text { for some } \lambda \in Q_{\xi}(q, d)
$$

\footnotetext{
${ }^{8}$ Note that shareholder disagreement would not be an issue if one assumed privately owned firms, as in Angeletos (2007) and Angeletos and Calvet (2005, 2006).

${ }^{9}$ Following the seminal paper of Diamond (1967), several authors have proposed alternative objectives of the firm. For example, Dreze (1974) and Grossmann and Hart (1979) assume a different discount factor; Dreze (1985) and DeMarzo (1993) propose a control mechanism based on majority voting; Radner (1972a), Sandmo (1972), Sondermann (1974) or Leland (1972) assume a a utility function for the firm, defined exogenously over profits.
} 
This approach has also been followed by DeMarzo (1988) and Duffie and Shaffer (1986b), who study the validity of the Modigliani-Miller theorem and the existence of equilibrium and shareholder agreement in a general incomplete markets context. As noted by the authors, one could alternatively assume that the firm maximizes its share price according to some valuation function that assigns a price process to a given stream of cash flows. Further, as long as this valuation does not predict security prices that allow for arbitrage opportunities, there exist some positive present value prices $\lambda \in Q_{\xi}(q, d)$ such that the valuation conjectured by the firm is equal to the objective function above.

The optimization problem under value maximization can be characterized by the following necessary and sufficient first order conditions:

$$
\begin{gathered}
w(\xi)=f_{n}\left(z(\xi), k\left(\xi^{-}\right), n(\xi)\right) \\
1=\sum_{\xi^{\prime} \in \xi^{+}} \frac{\lambda\left(\xi^{\prime}\right)}{\lambda(\xi)}\left[f_{k}\left(z\left(\xi^{\prime}\right), k(\xi), n\left(\xi^{\prime}\right)\right)+1-\delta\right]
\end{gathered}
$$

The first equation states that the firm will hire labor up to the point where its marginal product equals the wage rate. The second equation determines the optimal investment plan and it illustrates that the intertemporal investment decision in this economy is made by the firm.

The e-economy is specified by a set of preferences $\succsim$, initial values $\left(k_{0}, a_{0}, z_{0}, \epsilon_{0}\right)=$ $\left\{k\left(\xi_{-1}\right),\left(a_{i}\left(\xi_{-1}\right), \epsilon_{i}\left(\xi_{0}\right)\right)_{i \in I}, z\left(\xi_{0}\right)\right\}$, a transition matrix $\Pi$, security processes $d^{a}=\left(d^{j}\right)_{j \geq 2}$ and limits $B=\left(B_{i}\right)_{i \in I}$. The $e$-economy is then described by $E_{e}=\left\{\succsim,\left(k_{0}, a_{0}, z_{0}, \epsilon_{0}\right), \Pi, d^{a}, B\right\}$.

Definition 2.2. The vector of processes $\left\{\left(c_{i}, a_{i}\right)_{i \in I}, q, w, k\right\}$ is a value maximizing $\mathrm{CE}$ (VM CE) for $E_{e}$ if:

(i) For each $i \in I$ and for each $\xi \in D,\left(c_{i}, a_{i}\right)_{i \in I}$ is optimal under the preferences $\succsim$ given $(q, w),\left(k_{0}, a_{0}, z_{0}, \epsilon_{0}\right), \Pi, d^{a}$ and $B$.

(ii) $(w, k)$ satisfies the firm's optimality conditions for some $\lambda \in Q_{\xi}(q, d)$.

(iii) all markets clear, i.e., for all $\xi \in D, n(\xi)=\sum_{i \in I} \epsilon_{i}(\xi), \sum_{i \in I} a_{i}^{j}(\xi)=A^{j}$ for $j \in J$ and $\sum_{i \in I} c_{i}(\xi)=w_{c}(\xi)=w(\xi) n(\xi)+d(\xi) A$.

Two important remarks are worth noting. First, the previous equilibrium definition implies that the set of allowable present value processes $Q_{\xi}(q, d)$ that the firm can use to discount its net cash flows has to satisfy a fixed point problem in the following sense. When the firm discounts profits with some $\lambda$ that belongs to the set of admissible present value prices $Q_{\xi}(q, d)$, its production choice $k(\lambda)$ generates a new asset structure $(q(\lambda), d(\lambda))$ and a new set of admissible present value prices $Q_{\xi}(q(\lambda), d(\lambda))$ to which the original $\lambda$ has to belong. Thus, if we define a mapping from the admissible set of present value prices to the set of present value prices that it generates, the equilibrium set of discount factors can be seen as a fixed point of this mapping. Moreover, if the set satisfying the previous fixed point problem is not single valued, the presence of incomplete financial markets might generate indeterminacy of equilibria with respect to the firm discount factor (see Duffie and Shaffer (1986b)).

Second, since the state process $\lambda$ can be interpreted as the discount factor used by the firm to value future net cash flows, value maximization will generate shareholder disagreement if $\lambda$ does not agree with the valuation of the controllers of the firm. Note, however, that this disagreement is only with respect to the firm's choice of investment plan $\{k\}$, which involves an intertemporal tradeoff. In contrast, the firm's choice of labor $\{n\}$ is a static one, and all the shareholders will agree on choosing the labor quantity that satisfies (17) and equates the marginal product of labor to the aggregate wage rate. 
Notice that the equilibrium concept in Definition 2.2 does not take into account the relationship between the investment decision of the firm and its ownership structure. In other words, the investment decisions could potentially be made without taking into account the preferences of the shareholders. To address this issue, we let $I^{c}(\xi) \subseteq I$ be the subset of shareholders that have control over the firm at $\xi$, in the sense that they own positive shares of the firm. We can now extend the previous equilibrium definition to an equilibrium concept with shareholder agreement, by replacing condition (ii) in Definition 2.2 with the following condition: (ii)' $(w, k)$ satisfies the firm's optimality conditions for some $\lambda \in Q_{\xi}(q, d)$ that coincides with the valuation of future cash flows of all $i \in I^{c}(\xi)$. If this condition is satisfied, a investment plan that is unilaterally chosen by the value maximizing firm also maximizes the utility of the shareholders in the control group. The issue of shareholder disagreement in the present setting will be discussed in Section $4 .^{10}$

\section{Equivalence of the Production Allocations}

This section shows the equivalence of the set of equilibria in the two production economies under the objective of value maximization. As discussed in the previous section, the main difference between the $e$-economy and the $k$-economy is that consumers purchase shares of the firms' stock in the former, while they accumulate capital directly in the latter. We first show that, in a $\mathrm{CE}$ of the e-economy, bubbles can be ruled out for any consistent present value process and for any security that is in positive supply (Proposition 3.1). As a consequence, the stock price is equal to its fundamental value, while the discounted value of capital converges to zero as time goes to infinitity. This, together with the assumption of constant returns to scale and the objective of value maximization, implies that the firm's stock price in the $e$-economy is equal to its physical capital stock (Proposition 3.2). Thus, when consumers purchase firm's shares, they are simply purchasing units of capital through the firm. The equivalence of allocations can then be proven by showing that the agents' budget constraints, the first order conditions and the market clearing conditions are the same in the two economies (Theorems 3.1 and 3.2).

The next proposition establishes that in a $\mathrm{CE}$ of the $e$-economy there are no bubbles for any consistent present value process and for any security that is in positive supply. ${ }^{11}$

Proposition 3.1 Consider a CE for $E_{e}$. For each node $\xi \in D$ and for each security $j \in J$ traded at $\xi$ that is in positive net supply, we have that:

$$
q^{j}(\xi)=v_{d^{j}}(\xi, \lambda) \text { for all } \lambda \in Q_{\xi}(q, d) .
$$

Moreover, the following is true:

$$
\lim _{\widetilde{T} \rightarrow \infty} \sum_{\xi^{\prime} \in D^{+}(\xi), t\left(\xi^{\prime}\right)=\widetilde{T}} \frac{\lambda\left(\xi^{\prime}\right)}{\lambda(\xi)} k\left(\xi^{\prime}\right)=0 \text { for all } \lambda \in Q_{\xi}(q, d) .
$$

\section{Proof. See Appendix.}

The results of the previous proposition can be established in two steps. First, following Santos and Woodford (1997), it can be shown that bubbles on assets that are in positive net supply cannot exist if there exists a consistent process $\lambda \in Q_{\xi}(q, d)$ such that the present

\footnotetext{
${ }^{10}$ An excellent survey on the existing unanimity results and a discussion of shareholder disagreement under value maximization is provided in Grossman and Stiglitz (1977, 1980). Further, see Duffie and Shafer (1986) for a discussion of unanimity under value maximization in a general multiperiod setup, and Carceles-Poveda and Coen-Pirani (2008) for a discussion of unanimity in a finite period version of the present setting.

${ }^{11}$ It is straightforward to show that bubbles can be ruled out for any security with a finite-maturity, such as the one-period bonds that are typically traded in macroeconomic models.
} 
value of the aggregate labor endowment $v_{w_{n}}(\xi, \lambda)$ is finite when this state price process is used. Second, in the presence of trade in a claim to productive activity, it can be shown that the present value of the aggregate labor endowment is finite for any consistent present value process. These two results then imply that bubbles cannot exist for any security that is in positive supply, ruling out stock price bubbles in the $e$-economy. ${ }^{12}$

The next proposition shows that the aggregate capital stock $k$ chosen by a value maximizing firm in the $e$-economy is equal to the ex-dividend firm value $q^{1}$.

Proposition 3.2 If the e-economy firm discounts its net cash flows with some $\lambda \in$ $Q_{\xi}(q, d)$, the equilibrium investment plan satisfies:

$$
k(\xi)=q^{1}(\xi) \text { for all } \xi \in D .
$$

Proof. To prove the proposition, recall that the first order conditions of the firm's problem under value maximization imply that:

$$
1=\sum_{\xi^{\prime} \in \xi^{+}} \frac{\lambda\left(\xi^{\prime}\right)}{\lambda(\xi)} F_{k}\left(z\left(\xi^{\prime}\right), k(\xi), n\left(\xi^{\prime}\right)\right)
$$

where $\lambda \in Q_{\xi}(q, d)$. Multiplying the previous expression by $k(\xi)$, adding and subtracting $k\left(\xi^{\prime}\right)$ on the right hand side, and using the homogeneity condition of the production function, we obtain:

$$
k(\xi)=\sum_{\xi^{\prime} \in \xi^{+}} \frac{\lambda\left(\xi^{\prime}\right)}{\lambda(\xi)}\left[d^{1}\left(\xi^{\prime}\right)+k\left(\xi^{\prime}\right)\right]
$$

Further, substituting iteratively for $k\left(\xi^{\prime}\right)$ for $\xi^{\prime} \in D^{+}(\xi)$ with $t\left(\xi^{\prime}\right) \leq \widetilde{T}$, we have that:

$$
k(\xi)=\sum_{\xi^{\prime} \in D^{+}(\xi), t\left(\xi^{\prime}\right) \leq \widetilde{T}} \frac{\lambda\left(\xi^{\prime}\right)}{\lambda(\xi)} d^{1}\left(\xi^{\prime}\right)+\sum_{\xi^{\prime} \in D^{+}(\xi), t\left(\xi^{\prime}\right)=\widetilde{T}} \frac{\lambda\left(\xi^{\prime}\right)}{\lambda(\xi)} k\left(\xi^{\prime}\right)
$$

The first term on the right-hand side of the previous equation has a well-defined limit, and the second term converges to zero as $\widetilde{T}$ goes to infinity by Proposition 3.1. Thus, taking limits of the previous equation as $\widetilde{T}$ goes to infinity, the aggregate capital stock can be expressed as:

$$
k(\xi)=\sum_{\xi^{\prime} \in D^{+}(\xi)} \frac{\lambda\left(\xi^{\prime}\right)}{\lambda(\xi)} d^{1}\left(\xi^{\prime}\right),
$$

where the expression on the right-hand side is, by definition, equal to $v_{d^{1}}(\xi, \lambda)$. Further, since equity is in positive net supply, Proposition 3.1 also implies that $q^{1}(\xi)=v_{d^{1}}(\xi, \lambda)$ for all $\lambda \in Q_{\xi}(q, d)$, establishing the result.

Proposition 3.2 provides the basis for proving that equilibrium allocations in the $e$ and $k$ economies coincide. It is important to note that it depends crucially on the assumptions of constant returns to scale and value maximization. To see this, note first that the assumption of constant returns to scale in capital and labor, in conjunction with the fact that labor is chosen on a period-by-period basis as a function of the existing capital, implies that the

\footnotetext{
${ }^{12}$ As briefly discussed by Santos and Woodford (1997), who study the existence of price bubbles in exchange economies, bubbles can be ruled out in the presence of a claim to productive activity if one assumes that the ratio of dividends to output in each state of the world is bounded from below by a non-negative number. In the present setup, we provide an alternative proof of the absence of bubbles under an analogous assumption about dividends.
} 
technology is effectively a linear function of capital only. More precisely, the assumption of constant returns to scale implies that marginal product of labor $f_{n}(z, k, n)$ is homogenous of degree zero in $k$ and $n$. Thus, the optimal labor decision in (17) and the associated level of production can be expressed as:

$$
n(\xi)=k\left(\xi^{-}\right) g_{1}(z(\xi), w(\xi))
$$

and

$$
F\left(z(\xi), k\left(\xi^{-}\right), n(\xi)\right)=\left[f\left(z(\xi), 1, g_{1}(z(\xi), w(\xi))\right)+(1-\delta)\right] k\left(\xi^{-}\right),
$$

where $g_{1}$ is a function that is independent of $k\left(\xi^{-}\right)$.

In turn, with a linear production technology, the marginal and average products of capital of the firm coincide, implying that the effect of marginally increasing the capital stock on the present discounted value of dividends $v_{d^{1}}(\xi, \lambda)$ must be equal to the ratio of the latter to the amount of capital chosen by the firm. Note that, using the previous expressions, it is easy to see that the present value of dividends $v_{d^{1}}(\xi, \lambda)$ is linear in capital, since

$$
d^{1}(\xi)+k(\xi)=k\left(\xi^{-}\right) g_{2}(z(\xi), w(\xi))
$$

where the function $g_{2}$ is given by:

$$
g_{2}(z(\xi), w(\xi)) \equiv F\left(z(\xi), 1, g_{1}(z(\xi), w(\xi))\right)-w(\xi) g_{1}(z(\xi), w(\xi)) .
$$

Last, given that the relative price of an additional unit of capital is equal to one, by the equality of marginal benefits and marginal costs of investment at an optimal choice, the ratio of the present value of dividends to the capital stock must also be equal to one. In other words, the capital stock must be equal to the present value of dividends, $k(\xi)=v_{d^{1}}(\xi, \lambda)$. The equality between the firm's capital stock and its stock price then follows directly from Proposition 3.1. It is worth emphasizing that this last step is a consequence of the fact that a value maximizing firm discounts the future using a discount factor that is consistent with the stock price. ${ }^{13}$

In what follows, we first formally state the equivalence results by means of two theorems. Next, we provide intuition. To distinguish the allocations in the two economies, we let the caret bearing variables always denote $k$-economy allocations.

Theorem 3.1. Let $\left\{\left(c_{i}, a_{i}\right)_{i \in I}, q, w, k\right\}$ be a VM CE for $E_{e}=\left\{\succsim,\left(k_{0}, a_{0}, z_{0}, \epsilon_{0}\right), \Pi, d^{a}, B\right\}$. Then, there exist processes $\widehat{k}_{i}$ and $\widehat{r}$ such that $\left\{\left(c_{i}, \widehat{k}_{i},\left(a_{i}^{j}\right)_{j \geq 2}\right)_{i \in I},\left(q^{j}\right)_{j \geq 2}, w, \widehat{r}\right\}$ is a $\mathrm{CE}$ for $E_{k}=\left\{\succsim,\left(k_{0}, a_{0}, z_{0}, \epsilon_{0}\right), \Pi, d^{a}, B\right\}$. In particular, $\widehat{k}_{i}(\xi)=q^{1}(\xi) a_{i}^{1}(\xi)$ and $\widehat{r}(\xi)=$ $R^{1}(\xi) / q^{1}\left(\xi^{-}\right)$for all $\xi \in D$.

Proof. See Appendix.

Theorem 3.1 asserts that a value maximizing equilibrium in the e-economy is also an equilibrium in a $k$-economy with the same characteristics. Theorem 3.2 below states that the reverse is also true.

Theorem 3.2. Let $\left\{\left(\widehat{c}_{i}, \widehat{k}_{i},\left(\widehat{a}_{i}^{j}\right)_{j \geq 2}\right)_{i \in I},\left(\widehat{q}^{j}\right)_{j \geq 2}, \widehat{w}, r\right\}$ be a CE for the economy specified by $E_{k}=\left\{\succsim,\left(\widehat{k}_{0}, \widehat{a}_{0}, z_{0}, \epsilon_{0}\right), \Pi, \widehat{d}^{a}, \widehat{B}\right\}$. Then, there exist processes for $a_{i}^{1}$, and $q^{1}$ such that $\left\{\left(\widehat{c}_{i}, a_{i}^{1},\left(\widehat{a}_{i}^{j}\right)_{j \geq 2}\right)_{i \in I}, q^{1},\left(\widehat{q}^{j}\right)_{j \geq 2}, \widehat{w}, \widehat{k}\right\}$ is a VM CE for $E_{e}=\left\{\succsim,\left(\widehat{k}_{0}, \widehat{a}_{0}, z_{0}, \epsilon_{0}\right), \Pi, \widehat{d}^{a}, \widehat{B}\right\}$.

\footnotetext{
${ }^{13}$ Notice that the result of Proposition 3.2 also holds in a complete-markets economy under the same conditions on the production technology.
} 
In particular, $a_{i}^{1}(\xi)=\frac{\widehat{k}_{i}(\xi)}{\widehat{k}(\xi)}$ and $q^{1}(\xi)=\widehat{k}(\xi)=\sum_{i \in I} \widehat{k}_{i}(\xi)=\widehat{q}^{1}(\xi)$ for all $\xi \in D$.

Proof. See Appendix.

To gain further intuition for why the theorems are true, we first note that one of the important implications of Proposition 3.2 is that the rate of return on equity in the $e$ economy equals the return on accumulating physical capital:

$$
\frac{d^{1}\left(\xi^{\prime}\right)+q^{1}\left(\xi^{\prime}\right)}{q^{1}(\xi)}=F_{k}\left(z\left(\xi^{\prime}\right), k(\xi), n\left(\xi^{\prime}\right)\right) .
$$

Therefore, purchasing shares of the value-maximizing firm at a unit price of $q^{1}(\xi)$ in the e-economy stock market is equivalent, in the sense that it gives the same return, to accumulating a unit of physical capital in the $k$-economy. The equivalence of allocations can then be proven by comparing the first order conditions of the agents, their budget constraints and the market clearing conditions in the two economies.

First, consider the optimality conditions in the two economies. The allocation associated with the CE of the $k$-economy (see Definition 2.1) must be such that the following first order condition for capital accumulation holds for each agent $i$ :

$$
1 \geq \sum_{\xi^{\prime} \in \xi^{+}} \frac{\beta_{i} \pi\left(\xi^{\prime}\right)}{\pi(\xi)} \frac{u_{i}^{\prime}\left(\widehat{c}_{i}\left(\xi^{\prime}\right)\right)}{u_{i}^{\prime}\left(\widehat{c}_{i}(\xi)\right)} F_{k}\left(z\left(\xi^{\prime}\right), \widehat{k}(\xi), \widehat{n}\left(\xi^{\prime}\right)\right) .
$$

In addition, the allocation associated with the $\mathrm{CE}$ of the $e$-economy (see Definition 2.2) must be such that the following first order condition for the purchase of shares holds for each agent $i$ :

$$
1 \geq \sum_{\xi^{\prime} \in \xi^{+}} \frac{\beta_{i} \pi\left(\xi^{\prime}\right)}{\pi(\xi)} \frac{u_{i}^{\prime}\left(c_{i}\left(\xi^{\prime}\right)\right)}{u_{i}^{\prime}\left(c_{i}(\xi)\right)}\left[\frac{d^{1}\left(\xi^{\prime}\right)+q^{1}\left(\xi^{\prime}\right)}{q^{1}(\xi)}\right] .
$$

Proposition 3.2 guarantees that $q^{1}(\xi)=k(\xi)$. This, together with the fact that the returns on stocks and capital are the same (see equation 20) implies that the optimality condition in the e-economy can be re-written as:

$$
1 \geq \sum_{\xi^{\prime} \in \xi^{+}} \frac{\beta_{i} \pi\left(\xi^{\prime}\right)}{\pi(\xi)} \frac{u_{i}^{\prime}\left(c_{i}\left(\xi^{\prime}\right)\right)}{u_{i}^{\prime}\left(c_{i}(\xi)\right)} F_{k}\left(z\left(\xi^{\prime}\right), k(\xi), n\left(\xi^{\prime}\right)\right) .
$$

It follows that the first order conditions in equations (21) and (23) are formally identical.

Consider now the budget constraints of the agents in the $k$-economy (equations (12), (13), and (14)) and in the $e$-economy (equations (5), (6), and (7)). Notice that these equations differ for two reasons. First, since in the $k$-economy agents accumulate capital directly, the term $\widehat{k}_{i}(\xi)$ appears on the budget constraints of the $k$-economy, while the term $q_{1}(\xi) a_{i}^{1}(\xi)$ shows up in the budget constraints of the e-economy. Second, in the $k$-economy an agent receives a return $\widehat{r}\left(\xi^{\prime}\right)$ from each unit of capital $\widehat{k}_{i}(\xi)$ he owns, while in the $e$-economy agents receive a return $R^{1}\left(\xi^{\prime}\right)$ from each share of the firm $a_{i}^{1}(\xi)$ they own. Again, Proposition 3.2 allows us to show that both differences vanish due to the fact that $q_{1}(\xi)=k(\xi)$. In particular, let $k_{i}(\xi) \equiv a_{i}^{1}(\xi) k(\xi)$ be the value of the shares of the firm that agent $i$ owns at node $\xi$ in the $e$-economy and let $r\left(\xi^{\prime}\right)$ be the marginal product of capital at node $\xi^{\prime}$. The equality of gross returns of capital and stocks in equation (20) implies that the return on shares $R^{1}\left(\xi^{\prime}\right)$ equals the marginal product of capital times the firm's capital stock, $r\left(\xi^{\prime}\right) k(\xi)$. Using this, it is then straightforward to see that the budget constraints of the $e$-economy in the same form as the budget constraints of the $k$-economy. Finally, market clearing for shares of the 
firm in the $e$-economy requires that:

$$
\sum_{i \in I} a_{i}^{1}(\xi)=1
$$

Using the definition of $k_{i}(\xi)$, this is equivalent to:

$$
\sum_{i \in I} k_{i}(\xi)=k(\xi)
$$

which is the market clearing condition for the physical capital stock in the $k$-economy. ${ }^{14}$ These arguments establish that the two economies are characterized by the same first order conditions, budget constraints, and market clearing conditions. It then follows that the two $\mathrm{CE}$ allocations, if they exist, must be identical.

\section{Additional Remarks}

Theorems 3.1 and 3.2 extend to an incomplete markets setting with general portfolio restrictions the result, well-known under complete markets, that the equilibrium allocation is the same independently of whether consumers own the capital and rent it to the firm, or whether the latter accumulates and owns the capital stock directly. A few remarks are worth noting.

First, theorems 3.1 and 3.2 imply that value maximization leads to the same dimension of the set of equilibria in the two production economies. In general, however, the equilibrium allocation in the $e$-economy might depend on the particular firm discount factor $\lambda \in Q_{\xi}(q, d)$ (see Duffie and Shaffer (1986b)), in which case Theorem 3.1 shows that it is also an equilibrium allocation in the $k$-economy. On the other hand, the equivalence of allocations in the two economies guarantees that if a $\mathrm{CE}$ in the $k$-economy exists and is unique, the $e$-economy VM CE is invariant with respect to the firm discount factor $\lambda \in Q_{\xi}(q, d) .{ }^{15}$

Second, under the present value borrowing constraint, which is effectively never binding, there is unanimity among shareholders on the investment plan chosen by the firm. However, in the presence of binding borrowing constraints, the firm's investment plan is not necessarily unanimously approved by the shareholders that belong to the control group $I^{c}(\xi) \subseteq I$. This is due to the fact that the valuation of the firm does not coincide with the valuation of future profits by shareholders that are either constrained in the present or might be so in the future. In other words, a value maximizing equilibrium with shareholder agreement might not exist in the presence of binding portfolio restrictions. In spite of this, our main equivalence result still holds, implying that a value maximizing firm in the $e$-economy will choose the same investment plan as if households were making the intertemporal investment decision in the $k$-economy.

Last, our results can be easily extended to allow firms in the two production settings to raise capital by issuing different assets, such as bonds, for example. Firms might also be heterogeneous in their productivity processes. Moreover, in the $e$-economy heterogeneous firms may also differ in their discount factors as long as they belong to the set of consistent present value prices, which is common across firms. Using arguments similar to the ones in Proposition 3.1, price bubbles can be ruled out also in these two cases. Moreover, in the presence of external financing, the ex-divident value of the firm in the $e$-economy, defined as the market value of the assets in its capital structure, is equal to its capital stock. In the economy with heterogeneous firms, each firm $j$ will choose a capital stock equal to its market value, $k^{j}(\xi)=q^{j}(\xi)=v_{d^{j}}\left(\xi, \lambda^{j}\right)$ where $\lambda^{j} \in Q_{\xi}(q, d)$. Given this, the results of the

\footnotetext{
${ }^{14}$ Notice that the first order condition for the choice of labor by the firm is static and therefore identical in the two economies. Similarly, the exogenous supply of labor is the same.

${ }^{15}$ To our knowledge, there are no proofs of uniqueness for infinite horizon stochastic $k$-economies.
} 
previous section follow through in both cases. ${ }^{16}$

\section{Summary and Conclusions}

This paper characterizes the competitive equilibrium in a class of incomplete market economies where firms make the intertemporal investment decision and households are subject to general portfolio restrictions. In particular, it shows that economies with value maximizing firms that own the stock of physical capital have the same equilibrium allocations as the economies recently considered in the macroeconomic literature, in which firms rent the capital stock from the households on a period by period basis. Thus, our work can be viewed as establishing a link between the traditional GEI literature and the quantitative macroeconomic literature with incomplete markets.

Whereas value maximization is a natural objective, interesting issues may arise when the stock of physical capital does not coincide with the market value of the firm. In this case, otherwise similar incomplete market models might lead to different qualitative and quantitative implications with respect to the ones established in the macroeconomic literature. For example, authors like Aiyagari (1994) and Krusell and Smith $(1997,1998)$ have shown that imperfect risk sharing in the standard setting can lead to an increase in the aggregate capital stock due to precautionary savings. In contrast, if aggregate household wealth, which is equal to the stock market value of firms, is not the same as the aggregate capital stock, precautionary savings might not necessarily be reflected in a higher capital accumulation. ${ }^{17}$

Another context in which the fact that the aggregate capital stock and the value of the firm may not coincide could be particularly important is the overlapping generations setting with production. For example, Magill and Quinzii (2003) consider such a setting with irreversible capital investment and show that the economy's capital stock may converge to the efficient Golden rule steady state rather than to the suboptimal steady state.

The examples above suggest that the analysis of dynamic models featuring an explicit stock market is likely to provide new insights into the functioning of real-world economies. Thus, while our paper has provided sufficient conditions under which economies with static and dynamic firms behave in a similar manner, we think that it is still worthwhile exploring the contexts in which this equivalence breaks down. We leave this difficult task to future research.

\footnotetext{
${ }^{16}$ The proofs of these results can be found in the technical appendix accompanying the paper, which is available from the authors upon request.

${ }^{17}$ This point is illustrated by Carceles-Poveda (2007), who studies the quantitative implications of alternative objective functions for firms in a two agent model with incomplete markets. In such a framework, it is shown that the aggregate capital stock is very sensitive to the assumption on firm's objectives.
} 


\section{APPENDIX}

\section{Proof of Proposition 3.1}

(a) We first show that, if there exists a state prices process $\lambda \in Q_{\xi}(q, d)$ such that the present value of aggregate labor income $v_{w_{n}}(\xi, \lambda)$ is finite for every date-state $\xi$, then $q^{j}\left(\xi^{\prime}\right)=v_{d^{j}}\left(\xi^{\prime}, \lambda\right)$ for all $\xi^{\prime} \in D(\xi)$ and each security traded at date-state $\xi^{\prime}$ that is in positive net supply. To prove this, note that the preferences defined by $\succsim$ and satisfying assumption (A.4) have the following property, which is labelled a sufficient degree of impatience in the general equilibrium literature. For each $i \in I$, there exists a $0 \leq \gamma_{i}<1$ such that for any date state $\xi \in D$,

$$
\left(c_{i}^{-}(\xi), c_{i}(\xi)+w_{c}(\xi), \gamma c_{i}^{+}(\xi)\right) \succ\left(c_{i}^{-}(\xi), c_{i}(\xi), c_{i}^{+}(\xi)\right)
$$

for all consumption plans satisfying $c_{i}\left(\xi^{\prime}\right) \leq w_{c}\left(\xi^{\prime}\right)$ at each $\xi^{\prime} \in D$ and all $\gamma \geq \gamma_{i}$. Here, $\succ_{i}$ denotes strict preference, $c_{i}^{-}(\xi)$ denotes the consumption coordinates at all nodes other than the sub-tree nodes $\xi^{\prime} \in D^{+}(\xi)$, and $c_{i}^{+}(\xi)$ denotes the consumption coordinates at the nodes $\xi^{\prime} \in D^{+}(\xi)$. Given this, if the plan $\left(c_{i}, a_{i}\right)$ is optimal at $q$, we have that, for all $\xi$ :

$$
\left(1-\gamma_{i}\right) q(\xi)^{T} a_{i}(\xi) \leq w_{c}(\xi)
$$

To see that equation (2) is true, suppose that $\left(1-\gamma_{i}\right) q(\xi)^{T} a_{i}(\xi)>w_{c}(\xi)$ for some $\xi$. Household $i$ could then choose the alternative plan $\left(\widehat{c}_{i}, \widehat{a}_{i}\right)$ :

$$
\begin{aligned}
\left(\widehat{c}_{i}^{-}(\xi), \widehat{c}_{i}(\xi), \widehat{c}_{i}^{+}(\xi)\right) & =\left(c_{i}^{-}(\xi), c_{i}(\xi)+w_{c}(\xi), \gamma_{i} c_{i}^{+}(\xi)\right) \\
\left(\widehat{a}_{i}^{-}(\xi), \widehat{a}_{i}(\xi), \widehat{a}_{i}^{+}(\xi)\right) & =\left(a_{i}^{-}(\xi), \gamma_{i} a_{i}(\xi), \gamma_{i} a_{i}^{+}(\xi)\right)
\end{aligned}
$$

which is feasible and would be preferred to $\left(c_{i}, a_{i}\right)$ by equation (1), contradicting the fact that $\left(c_{i}, a_{i}\right)$ is optimal. Given this, equation (2) must hold. Next, we show that, for all $\xi$ :

$$
\sum_{\xi^{\prime} \in D^{+}(\xi)} \lambda\left(\xi^{\prime}\right) c_{i}\left(\xi^{\prime}\right) \geq \sum_{\xi^{\prime} \in D^{+}(\xi)} \lambda\left(\xi^{\prime}\right) w_{i}\left(\xi^{\prime}\right)+\lambda(\xi) q(\xi)^{T} a_{i}(\xi)
$$

To see that this is the case, we can multiply the date-state $\xi$ budget constraint of consumer $i$, satisfied with equality for each date-state given our assumptions on preferences, with some $\lambda \in Q_{\xi}(q, d)$ for which $v_{w}(\xi, \lambda)<+\infty$. Summing over all date-states $\xi^{\prime} \in D^{+}(\xi)$ with $t\left(\xi^{\prime}\right) \leq \widetilde{T}$, we obtain:

$$
\begin{aligned}
& \sum_{\xi^{\prime} \in D^{+}(\xi), t\left(\xi^{\prime}\right) \leq \widetilde{T}} \lambda\left(\xi^{\prime}\right) c_{i}\left(\xi^{\prime}\right)+\sum_{\xi^{\prime} \in D^{+}(\xi), t\left(\xi^{\prime}\right)=\widetilde{T}} \lambda\left(\xi^{\prime}\right) q^{T}\left(\xi^{\prime}\right) a_{i}\left(\xi^{\prime}\right) \\
& =\sum_{\xi^{\prime} \in D^{+}(\xi), t\left(\xi^{\prime}\right) \leq \widetilde{T}} \lambda\left(\xi^{\prime}\right) w_{i}\left(\xi^{\prime}\right)+\lambda(\xi) q(\xi)^{T} a_{i}(\xi)
\end{aligned}
$$

Substituting equation (2) and taking the limit of the previous equation as $\widetilde{T}$ goes to infinity, we have that:

$$
\begin{aligned}
& \lim _{\widetilde{T} \rightarrow \infty} \sum_{\xi^{\prime} \in D^{+}(\xi), t\left(\xi^{\prime}\right) \leq \widetilde{T}} \lambda\left(\xi^{\prime}\right) c_{i}\left(\xi^{\prime}\right)+\lim _{\widetilde{T} \rightarrow \infty}\left(1-\gamma_{i}\right)^{-1} \sum_{\xi^{\prime} \in D^{+}(\xi), t\left(\xi^{\prime}\right)=\widetilde{T}} \lambda\left(\xi^{\prime}\right) w_{c}\left(\xi^{\prime}\right) \\
\geq & \lim _{\widetilde{T} \rightarrow \infty} \sum_{\xi^{\prime} \in D^{+}(\xi), t\left(\xi^{\prime}\right) \leq \widetilde{T}} \lambda\left(\xi^{\prime}\right) w_{i}\left(\xi^{\prime}\right)+\lambda(\xi) q(\xi)^{T} a_{i}(\xi)
\end{aligned}
$$

Since $v_{w_{n}}(\xi, \lambda)<+\infty$ by assumption, it follows that $v_{w_{i}}(\xi, \lambda)<+\infty$ for all $i$, and the 
right hand side of the previous equation has a finite limit equal to $\lambda(\xi) v_{w_{i}}(\xi, \lambda)<+\infty$. Since $w_{n}(\xi)+d(\xi) A=w_{c}(\xi)$ and $v_{d A}(\xi, \lambda) \leq q(\xi)^{T} A<+\infty, v_{w_{n}}(\xi, \lambda)<+\infty$ also implies that $v_{w_{c}}(\xi, \lambda)<+\infty$, and it follows that $v_{c_{i}}(\xi, \lambda)<+\infty$ for all $i \in I$. Given this, the first term on the left hand side of the previous equation also has a well-defined and finite limit equal to $\lambda(\xi) v_{c_{i}}(\xi, \lambda)<+\infty$. Finally, since $v_{w_{c}}(\xi, \lambda)<+\infty$ and $w_{c}\left(\xi^{\prime}\right) \geq 0$ for all date-states $\xi^{\prime} \in$ $D^{+}\left(\xi^{\prime}\right)$ such that $t\left(\xi^{\prime}\right)=\widetilde{T}$, we have that $\lim _{\widetilde{T} \rightarrow \infty}\left(1-\gamma_{i}\right)^{-1} \sum_{\xi^{\prime} \in D^{+}(\xi), t\left(\xi^{\prime}\right)=\widetilde{T}} \lambda\left(\xi^{\prime}\right) w_{c}\left(\xi^{\prime}\right)=$ 0 , which establishes the inequality in equation (3). Summing the inequality over households, we obtain:

$$
\sum_{\xi^{\prime} \in D^{+}(\xi)} \lambda\left(\xi^{\prime}\right) c\left(\xi^{\prime}\right) \geq \sum_{\xi^{\prime} \in D^{+}(\xi)} \lambda\left(\xi^{\prime}\right) w_{n}\left(\xi^{\prime}\right)+\lambda(\xi) q(\xi)^{T} A
$$

Finally, substituting for $c(\xi)=w(\xi) n(\xi)+d(\xi) A$, we have that:

$$
\sum_{\xi^{\prime} \in D^{+}(\xi)} \frac{\lambda\left(\xi^{\prime}\right)}{\lambda(\xi)} d\left(\xi^{\prime}\right) A \geq q(\xi)^{T} A
$$

On the other hand, the fact that $v_{d^{j}}(\xi, \lambda) \leq q^{j}(\xi)$ for all $j \in J$ implies that

$$
\sum_{\xi^{\prime} \in D^{+}(\xi)} \frac{\lambda\left(\xi^{\prime}\right)}{\lambda(\xi)} d\left(\xi^{\prime}\right) A \leq q(\xi)^{T} A
$$

Therefore, $\sigma(\xi, \lambda)^{T} A=0$, where $\sigma(\xi, \lambda)^{T}=\left(\sigma^{1}(\xi, \lambda), \ldots \sigma^{J}(\xi, \lambda)\right)^{T}$, and $\sigma^{j}(\xi, \lambda)=0$ if $A^{j} \in \mathbb{R}_{++}$.

(b) We now show that $v_{w_{n}}(\xi, \lambda)<+\infty$ and $\lim _{\widetilde{T} \rightarrow \infty} \sum_{\xi^{\prime} \in D^{+}(\xi), t\left(\xi^{\prime}\right)=\widetilde{T}} \frac{\lambda\left(\xi^{\prime}\right)}{\lambda(\xi)} k\left(\xi^{\prime}\right)=0$ for all $\xi$ and all $\lambda \in Q_{\xi}(q, d)$. To prove this, note that, in equilibrium,

$$
d^{1}(\xi)=F\left(z(\xi), k\left(\xi^{-}\right), n(\xi)\right)-w(\xi) n(\xi)-k(\xi) \geq 0
$$

Given that $v_{d^{1}}(\xi, \lambda) \leq q^{1}(\xi)<+\infty$ for all $\xi \in D$ and all $\lambda \in Q_{\xi}(q, d)$, we have that, for all $\lambda \in Q_{\xi}(q, d)$ :

$$
\sum_{\xi^{\prime} \in D^{+}(\xi)} \frac{\lambda\left(\xi^{\prime}\right)}{\lambda(\xi)}\left[F\left(z\left(\xi^{\prime}\right), k(\xi), n\left(\xi^{\prime}\right)\right)-w\left(\xi^{\prime}\right) n\left(\xi^{\prime}\right)-k\left(\xi^{\prime}\right)\right]<+\infty
$$

Suppose now that $v_{w_{n}}(\xi, \lambda)=+\infty$ for some $\lambda \in Q_{\xi}(q, d)$. Since the previous inequality holds for every $\lambda \in Q_{\xi}(q, d)$, this would imply that:

$$
\sum_{\xi^{\prime} \in D^{+}(\xi)} \frac{\lambda\left(\xi^{\prime}\right)}{\lambda(\xi)}\left[F\left(z\left(\xi^{\prime}\right), k(\xi), n\left(\xi^{\prime}\right)\right)-k\left(\xi^{\prime}\right)\right]=+\infty
$$

On the other hand, equation (7) implies that the equity dividends can be expressed as a fraction $\phi(\xi)$ of output net of investment, i.e., $d^{1}(\xi)=\phi(\xi) x(\xi)$, where $x(\xi)=$ $\left[F\left(z(\xi), k\left(\xi^{-}\right), n(\xi)\right)-k(\xi)\right]$. Let $\phi=\inf _{\xi} \phi(\xi)>0$, where the last inequality follows from the fact that the productive dividend payments are bounded away from zero. Given this, we have that:

$$
d^{1}(\xi) \geq \phi\left[F\left(z(\xi), k\left(\xi^{-}\right), n(\xi)\right)-k(\xi)\right]
$$

implying that

$$
\phi \sum_{\xi^{\prime} \in D^{+}(\xi)} \frac{\lambda\left(\xi^{\prime}\right)}{\lambda(\xi)}\left[F\left(z\left(\xi^{\prime}\right), k(\xi), n\left(\xi^{\prime}\right)\right)-k\left(\xi^{\prime}\right)\right] \leq v_{d^{1}}(\xi, \lambda)<+\infty
$$


which contradicts equation (9). Therefore, it follows that $v_{w_{n}}(\xi, \lambda)<+\infty$ for all $\lambda \in Q_{\xi}(q, d)$. Finally, to see that

$$
\lim _{\widetilde{T} \rightarrow \infty} \sum_{\xi^{\prime} \in D^{+}(\xi), t\left(\xi^{\prime}\right)=\widetilde{T}} \frac{\lambda\left(\xi^{\prime}\right)}{\lambda(\xi)} k\left(\xi^{\prime}\right)=0
$$

for all $\lambda \in Q_{\xi}(q, d)$, note that this follows directly from (a) in the $k$-economy. Further, to show that this is also the case in the e-economy, note that $w(\xi) n(\xi)+d^{1}(\xi)+k(\xi)=$ $F\left(z(\xi), k\left(\xi^{-}\right), n(\xi)\right)$. Given this, we can use the same arguments as above to show that for some $\phi>0$, we have that $w(\xi) n(\xi) \geq \phi\left[F\left(z(\xi), k\left(\xi^{-}\right), n(\xi)\right)\right]$. This clearly implies that the first infinite sum in equation (9) is finite for every $\lambda \in Q_{\xi}(q, d)$. Therefore, for the total sum to be finite, it must be the case that:

$$
\sum_{\xi^{\prime} \in D^{+}(\xi)} \frac{\lambda\left(\xi^{\prime}\right)}{\lambda(\xi)} k\left(\xi^{\prime}\right)<+\infty
$$

implying that $\lim _{\widetilde{T} \rightarrow \infty} \sum_{\xi^{\prime} \in D^{+}(\xi), t\left(\xi^{\prime}\right)=\widetilde{T}} \frac{\lambda\left(\xi^{\prime}\right)}{\lambda(\xi)} k\left(\xi^{\prime}\right)=0$ for every $\lambda \in Q_{\xi}(q, d)$

To prove theorems 3.1 and 3.2, we will use the following Lemma.

Lemma A Consider optimal allocations in the $k$ - and e-economies. Further, assume that $\left(k_{0}, a_{0}, z_{0}, \epsilon_{0}\right), \Pi,\left(d^{j}, q^{j}\right)_{j>2}, B$ and $k$ are the same. If the firm in the $e$-economy has a value maximizing objective, the set of budget feasible allocations is the same in the two production economies.

Proof of Lemma A. To prove the lemma, let $\widehat{F}_{i}(\xi)$ and $F_{i}(\xi)$ be the set of budget feasible allocations at $\xi$ in the two production economies. Note first that $\widehat{c}_{i}(\xi) \in \widehat{F}_{i}(\xi)$ if there exists a set of portfolio strategies $\left\{\widehat{k}_{i},\left(\widehat{a}_{i}^{j}\right)_{j \geq 2}\right\}_{i \in I}$ such that, for all $\xi \in D$ and all $i \in I$ :

$$
\begin{gathered}
\widehat{c}_{i}(\xi)+\widehat{k}_{i}(\xi)+\sum_{j \geq 2} \widehat{q}^{j}(\xi) \widehat{a}_{i}^{j}(\xi) \leq \widehat{\omega}_{i}(\xi) \\
\widehat{\omega}_{i}\left(\xi^{\prime}\right)=\widehat{w}_{i}\left(\xi^{\prime}\right)+\left[f_{k}\left(z\left(\xi^{\prime}\right), \widehat{k}(\xi), \widehat{n}\left(\xi^{\prime}\right)\right)+1-\delta\right] \widehat{k}_{i}(\xi)+\sum_{j \geq 2} \widehat{R}^{j}\left(\xi^{\prime}\right) \widehat{a}_{i}^{j}(\xi) \text { for } \xi^{\prime} \in \xi^{+} \\
\widehat{k}_{i}(\xi)+\sum_{j \geq 2} \widehat{q}^{j}(\xi) \widehat{a}_{i}^{j}(\xi) \geq \widehat{B}_{i}(\xi)
\end{gathered}
$$

where we have substituted for the equilibrium values of $\widehat{r}\left(\xi^{\prime}\right)=f_{k}\left(z\left(\xi^{\prime}\right), \widehat{k}(\xi), \widehat{n}\left(\xi^{\prime}\right)\right)+1-\delta$. Similarly, $c_{i}(\xi) \in F_{i}(\xi)$ if there exists a set of portfolio strategies $\left(a_{i}^{j}\right)_{j \geq 1}$ such that, for all $\xi$ and all $i \in I$ :

$$
\begin{gathered}
c_{i}(\xi)+q^{1}(\xi) a_{i}^{1}(\xi)+\sum_{j \geq 2} q^{j}(\xi) a_{i}^{j}(\xi) \leq \omega_{i}(\xi) \\
\omega_{i}\left(\xi^{\prime}\right)=w_{i}\left(\xi^{\prime}\right)+\left[f_{k}\left(z\left(\xi^{\prime}\right), k(\xi), n\left(\xi^{\prime}\right)\right)+1-\delta\right] q^{1}(\xi) a_{i}^{1}(\xi)+\sum_{j \geq 2} R^{j}\left(\xi^{\prime}\right) a_{i}^{j}(\xi) \text { for } \xi^{\prime} \in \xi^{+} \\
q^{1}(\xi) a_{i}^{1}(\xi)+\sum_{j \geq 2} q^{j}(\xi) a_{i}^{j}(\xi) \geq B_{i}(\xi)
\end{gathered}
$$

where we have used homogeneity of the production function and the fact that $q^{1}(\xi)=k(\xi)$ by Proposition 3.2, implying that:

$$
q^{1}\left(\xi^{\prime}\right)+d^{1}\left(\xi^{\prime}\right)=\left(f_{k}\left(z\left(\xi^{\prime}\right), k(\xi), n\left(\xi^{\prime}\right)\right)+1-\delta\right) k(\xi)
$$

Let $\widehat{c}_{i}(\xi) \in \widehat{F}_{i}(\xi)$ and assume that the hypothesis of the lemma are satisfied. We now 
show that a plan setting $c_{i}(\xi)=\widehat{c}_{i}(\xi)$ at each node is feasible in the $e$-economy. To see this, consider any date-state $\xi \in D$. If $\omega_{i}(\xi)=\widehat{\omega}_{i}(\xi)$, households can choose the portfolio $a_{i}^{j}(\xi)=\widehat{a}_{i}^{j}(\xi)$ for $j \geq 2$ and $q^{1}(\xi) a_{i}^{1}(\xi)=\widehat{k}_{i}(\xi)$, implying that:

$$
\begin{aligned}
\widehat{c}_{i}(\xi)+q^{1}(\xi) a_{i}^{1}(\xi)+\sum_{j \geq 2} q^{j}(\xi) a_{i}^{j}(\xi) & =\widehat{c}_{i}(\xi)+\widehat{k}_{i}(\xi)+\sum_{j \geq 2} \widehat{q}^{j}(\xi) \widehat{a}_{i}^{j}(\xi) \leq \widehat{\omega}_{i}(\xi)=\omega_{i}(\xi) \\
q^{1}(\xi) a_{i}^{1}(\xi)+\sum_{j \geq 2} q^{j}(\xi) a_{i}^{j}(\xi) & =\widehat{k}_{i}(\xi)+\sum_{j \geq 2} \widehat{q}^{j}(\xi) \widehat{a}_{i}^{j}(\xi) \geq \widehat{B}_{i}(\xi)=B_{i}(\xi)
\end{aligned}
$$

Further, if household $i \in I$ chooses this portfolio, his wealth at the beginning of next period will be equal to:

$$
\omega_{i}\left(\xi^{\prime}\right)=\widehat{w}_{i}\left(\xi^{\prime}\right)+\left[f_{k}\left(z\left(\xi^{\prime}\right), \widehat{k}(\xi), \widehat{n}\left(\xi^{\prime}\right)\right)+(1-\delta)\right] \widehat{k}_{i}(\xi)+\sum_{j \geq 2} \widehat{R}^{j}\left(\xi^{\prime}\right) \widehat{a}_{i}^{j}(\xi)=\widehat{\omega}_{i}\left(\xi^{\prime}\right) \text { for } \xi^{\prime} \in \xi^{+}
$$

where we have used the fact that $w_{i}\left(\xi^{\prime}\right)=\widehat{w}_{i}\left(\xi^{\prime}\right)$ and $n\left(\xi^{\prime}\right)=\widehat{n}\left(\xi^{\prime}\right)$. Therefore, $c_{i}\left(\xi^{\prime}\right)=\widehat{c}_{i}\left(\xi^{\prime}\right)$ is also feasible in the e-economy at date-state $\xi^{\prime} \in \xi^{+}$. Finally, if the initial values are the same, implying that $k\left(\xi_{-1}\right) a_{i}^{1}\left(\xi_{-1}\right)=\widehat{k}_{i}\left(\xi_{-1}\right)$, the period zero wealth of household $i \in I$ in the e-economy is given by:

$$
\begin{aligned}
\omega_{i}\left(\xi_{0}\right) & =\sum_{j \geq 2} q^{j}\left(\xi_{0}\right) a_{i}^{j}\left(\xi_{-1}\right)+w_{i}\left(\xi_{0}\right)+\left[\left(f_{k}\left(z\left(\xi_{0}\right), k\left(\xi_{-1}\right), n\left(\xi_{0}\right)\right)+(1-\delta)\right) k\left(\xi_{-1}\right)\right] a_{i}^{1}\left(\xi_{-1}\right) \\
& =\sum_{j \geq 2} \widehat{q}^{j}\left(\xi_{0}\right) \widehat{a}_{i}^{j}\left(\xi_{-1}\right)+\widehat{w}_{i}\left(\xi_{0}\right)+\left[f_{k}\left(z\left(\xi_{0}\right), \widehat{k}\left(\xi_{-1}\right), \widehat{n}\left(\xi_{0}\right)\right)+(1-\delta)\right] \widehat{k}_{i}\left(\xi_{-1}\right)=\widehat{\omega}_{i}\left(\xi_{0}\right)
\end{aligned}
$$

Since $\omega_{i}\left(\xi_{0}\right)=\widehat{\omega}_{i}\left(\xi_{0}\right)$, it follows that $c_{i}\left(\xi_{0}\right)=\widehat{c}_{i}\left(\xi_{0}\right)$ is feasible, implying that $\widehat{c}_{i}(\xi) \in F_{i}(\xi)$ at all $\xi \in D$. Conversely, assume that $c_{i}(\xi) \in F_{i}(\xi)$ and consider any date-state $\xi \in D$. If $\widehat{\omega}_{i}(\xi)=\omega_{i}(\xi)$, households in the $k$-economy can choose the portfolio $\widehat{a}_{i}^{j}(\xi)=a_{i}^{j}(\xi)$ for $j \geq 2$ and $\widehat{k}_{i}(\xi)=q^{1}(\xi) a_{i}^{1}(\xi)$, achieving the same consumption allocation as in the $e$-economy at date-state $\xi$, since:

$$
\begin{gathered}
c_{i}(\xi)+\widehat{k}_{i}(\xi)+\sum_{j \geq 2} \widehat{q}^{j}(\xi) \widehat{a}_{i}^{j}(\xi)=c_{i}(\xi)+q^{1}(\xi) a_{i}^{1}(\xi)+\sum_{j \geq 2} q^{j}(\xi) a_{i}^{j}(\xi) \leq \omega_{i}(\xi)=\widehat{\omega}_{i}(\xi) \\
\widehat{k}_{i}(\xi)+\widehat{q}^{j}(\xi) \widehat{a}_{i}^{j}(\xi)=q^{1}(\xi) a_{i}^{1}(\xi)+q^{j}(\xi) a_{i}^{j}(\xi) \geq B_{i}(\xi)=\widehat{B}_{i}(\xi)
\end{gathered}
$$

Further, since $\widehat{w}_{i}\left(\xi^{\prime}\right)=w_{i}\left(\xi^{\prime}\right)$ and $\widehat{n}\left(\xi^{\prime}\right)=n\left(\xi^{\prime}\right)$, this will lead to the same wealth next period, i.e.,

$$
\widehat{\omega}_{i}\left(\xi^{\prime}\right)=w_{i}\left(\xi^{\prime}\right)+\left[f_{k}\left(z\left(\xi^{\prime}\right), k(\xi), n\left(\xi^{\prime}\right)\right)+(1-\delta)\right] q^{1}(\xi) a_{i}^{1}(\xi)+\sum_{j \geq 2} R^{j}\left(\xi^{\prime}\right) a_{i}^{j}(\xi) \text { for } \xi^{\prime} \in \xi^{+}
$$

Since $\widehat{\omega}_{i}\left(\xi^{\prime}\right)=\omega_{i}\left(\xi^{\prime}\right)$, we again have that $c_{i}\left(\xi^{\prime}\right)=\widehat{c}_{i}\left(\xi^{\prime}\right)$ is feasible in the $k$-economy at date state $\xi^{\prime} \in \xi^{+}$. Finally, since $\widehat{\omega}_{i}\left(\xi_{0}\right)=\omega_{i}\left(\xi_{0}\right)$, it follows that $c_{i}\left(\xi_{0}\right)=\widehat{c}_{i}\left(\xi_{0}\right)$ is feasible, and $c_{i}(\xi) \in \widehat{F}_{i}(\xi)$ at all nodes.

\section{Proof of Theorem 3.1}

Let $\left\{\left(c_{i}, a_{i}\right)_{i \in I}, q, w, k\right\}$ be a VM CE for $E_{e}=\left\{\succsim,\left(k_{0}, a_{0}, z_{0}, \epsilon_{0}\right), \Pi, d^{a}, B\right\}$. To show that $\left.\left\{c_{i}, \widehat{k}_{i},\left(a_{i}^{j}\right)_{j \geq 2}\right)_{i \in I},\left(q^{j}\right)_{j \geq 2}, w, \widehat{r}\right\}$ with $\widehat{r}(\xi)=R^{1}(\xi) / q^{1}\left(\xi^{-}\right)$and $\widehat{k}_{i}(\xi)=q^{1}(\xi) a_{i}^{1}(\xi)$ for all $\xi \in D$ is a $\mathrm{CE}$ for $E_{k}=\left\{\succsim,\left(k_{0}, a_{0}, z_{0}, \epsilon_{0}\right), \Pi, d^{a}, B\right\}$, note first that the aggregate capital in 
the $k$-economy is given by:

$$
\widehat{k}(\xi)=\sum_{i \in I} \widehat{k}_{i}(\xi)=\sum_{i \in I} q^{1}(\xi) a^{1}(\xi)=q^{1}(\xi)=k(\xi)
$$

where the last equality holds by Proposition 3.1. Further, we have used the fact that $a_{i}^{1}$ generates market clearing in the $e$-economy. Given this, the two factor prices:

$$
\begin{gathered}
w(\xi)=f_{n}\left(z(\xi), k\left(\xi^{-}\right), n(\xi)\right) \\
\widehat{r}(\xi)=R^{1}(\xi) / q^{1}\left(\xi^{-}\right)=\left(d^{1}(\xi)+k(\xi)\right) / k\left(\xi^{-}\right)=f_{k}\left(z(\xi), k\left(\xi^{-}\right), n(\xi)\right)+1-\delta
\end{gathered}
$$

satisfy the firm's optimality conditions in the $k$-economy, where we have substituted for the labor market clearing conditions and have again used Proposition 3.2. Second, since $\left(k_{0}, a_{0}, z_{0}, \epsilon_{0}\right), \Pi, d^{a}, B,\left(q^{j}\right)_{j \geq 2}$ and $k$ are the same across the two production economies, lemma A implies that $\widehat{F}_{i}(\xi)=F_{i}(\xi)$ for all $i \in I$ and all $\xi \in D$. Thus, the fact that $c_{i}$ is optimal for each $i \in I$ in the $e$-economy implies that it is also optimal for each $i \in I$ in the $k$-economy. In addition, the portfolio strategies achieving this allocation, given by $\widehat{a}_{i}^{j}(\xi)=a_{i}^{j}(\xi)$ for $j \geq 2$ and $\widehat{k}_{i}(\xi)=q^{1}(\xi) a^{1}(\xi)$, are optimal. To see that they satisfy the portfolio constraints, note that:

$$
\sum_{j \geq 2} \widehat{q}^{j}(\xi) \widehat{a}_{i}^{j}(\xi)+\widehat{k}_{i}(\xi)=\sum_{j \geq 2} q^{j}(\xi) a_{i}^{j}(\xi)+q^{1}(\xi) a^{1}(\xi) \geq B_{i}(\xi)=\widehat{B}_{i}(\xi)
$$

Finally, the fact that $\left(c_{i}, a_{i}\right)$ generates market clearing in the $e$-economy implies that the allocations still clear the markets in the $k$-economy. To see this, note that:

$$
\begin{gathered}
\sum_{i \in I} \widehat{c}_{i}(\xi)=\sum_{i \in I} c_{i}(\xi)=F\left(z(\xi), k\left(\xi^{-}\right), n(\xi)\right)-k(\xi)+\sum_{j \geq 2} d^{j}(\xi) A^{j}=w_{c}(\xi)=\widehat{w}_{c}(\xi) \\
\sum_{i \in I} \widehat{a}_{i}^{j}(\xi)=\sum_{i \in I} a_{i}^{j}(\xi)=A^{j}=\widehat{A}^{j} \text { for } j \geq 2 \\
\sum_{i \in I} \widehat{k}_{i}(\xi)=\sum_{i \in I} q^{1}(\xi) a_{i}^{1}(\xi)=q^{1}(\xi)=k(\xi)=\widehat{k}(\xi)
\end{gathered}
$$

This establishes the result.

\section{Proof of Theorem 3.2}

Let $\left\{\left(\widehat{c}_{i}, \widehat{k}_{i},\left(\widehat{a}_{i}^{j}\right)_{j \geq 2}\right)_{i \in I},\left(\widehat{q}^{j}\right)_{j \geq 2}, \widehat{w}, \widehat{r}\right\}$ be a CE for $E_{k}=\left\{\succsim,\left(\widehat{k}_{0}, \widehat{a}_{0}, z_{0}, \epsilon_{0}\right), \Pi, \widehat{d}^{a}, \widehat{B}\right\}$. We now show that $\left\{\left(\widehat{c}_{i}, a_{i}^{1}\left(\widehat{a}_{i}^{j}\right)_{j \geq 2}\right)_{i \in I}, q^{1},\left(\widehat{q}^{j}\right)_{j \geq 2}, \widehat{w}, \widehat{k}\right\}$ with $a_{i}^{1}(\xi)=\frac{\widehat{k}_{i}(\xi)}{\widehat{k}(\xi)}$ and $q^{1}(\xi)=$ $\widehat{k}(\xi)=\widehat{q}^{1}(\xi)$ is a VE CE for $E_{e}=\left\{\succsim,\left(\widehat{k}_{0}, \widehat{a}_{0}, z_{0}, \epsilon_{0}\right), \Pi, \widehat{d}^{a}, \widehat{B}\right\}$. To prove this, note first that the absence of arbitrage implies that the aggregate capital stock in the $k$-economy satisfies the following condition:

$$
\widehat{k}(\xi)=\sum_{\xi^{\prime} \in \xi^{+}} \frac{\widehat{\lambda}\left(\xi^{\prime}\right)}{\widehat{\lambda}(\xi)}\left[f_{k}\left(z\left(\xi^{\prime}\right), \widehat{k}(\xi), \widehat{n}\left(\xi^{\prime}\right)\right) \widehat{k}(\xi)+(1-\delta) \widehat{k}(\xi)\right]
$$

for some $\widehat{\lambda} \in Q_{\xi}(\widehat{q}, \widehat{d})$, where we have substituted for:

$$
\widehat{R}^{1}(\xi)=\widehat{r}(\xi) \widehat{k}\left(\xi^{-}\right)=f_{k}\left(z(\xi), \widehat{k}\left(\xi^{-}\right), \widehat{n}(\xi)\right) \widehat{k}\left(\xi^{-}\right)+(1-\delta) \widehat{k}\left(\xi^{-}\right)
$$


Since $q^{1}(\xi)=\widehat{q}^{1}(\xi)$ and $d^{1}(\xi)=\widehat{d}^{1}(\xi)$ due to the fact that the aggregate capital stock is the same in the two economies, it follows that $Q_{\xi}(q, d)=Q_{\xi}(\widehat{q}, \widehat{d})$. Therefore, the following values of $k(\xi)$ and $w(\xi)$ satisfy the firm's optimality conditions in the $e$-economy for some $\lambda \in Q_{\xi}(q, d):$

$$
\begin{gathered}
k(\xi)=\widehat{k}(\xi)=\sum_{\xi^{\prime} \in \xi^{+}} \frac{\widehat{\lambda}\left(\xi^{\prime}\right)}{\widehat{\lambda}(\xi)}\left[f_{k}\left(z\left(\xi^{\prime}\right), \widehat{k}(\xi), \widehat{n}\left(\xi^{\prime}\right)\right)+(1-\delta)\right] \widehat{k}(\xi) \\
w(\xi)=\widehat{w}(\xi)=f_{n}\left(z(\xi), \widehat{k}\left(\xi^{-}\right), \widehat{n}(\xi)\right)
\end{gathered}
$$

Second, since $\left(\widehat{k}_{0}, \widehat{a}_{0}, z_{0}, \epsilon_{0}\right), \Pi, \widehat{d^{a}}, \widehat{B}, \widehat{q}^{a}, \widehat{k}$ are the same in the two economies, Proposition 3.2 implies that $F_{i}(\xi)=\widehat{F}_{i}(\xi)$ for all $i \in I$ and all $\xi \in D$. Therefore, since $\widehat{c}_{i}$ is optimal for each $i \in I$ in the $k$-economy, it is also optimal for each $i \in I$ in the $e$-economy. In addition, this also implies that the portfolio strategies achieving this allocation $a_{i}^{j}(\xi)=\widehat{a}_{i}^{j}(\xi)$ for $j \geq 2$ and $a_{i}^{1}(\xi)=\widehat{k}_{i}(\xi) / \widehat{k}(\xi)$, implying that $q^{1}(\xi) a_{i}^{1}(\xi)=\widehat{k}_{i}(\xi)$, are optimal, and they also satisfy the portfolio constraints, since:

$$
\sum_{j \geq 2} q^{j}(\xi) a_{i}^{j}(\xi)+q^{1}(\xi) a_{i}^{1}(\xi)=\sum_{j \geq 2} \widehat{q}^{j}(\xi) \widehat{a}_{i}^{j}(\xi)+\widehat{k}_{i}(\xi) \geq \widehat{B}_{i}(\xi)=B_{i}(\xi)
$$

Finally, the fact that $\left\{\widehat{c}_{i}, k_{i},\left(\widehat{a}_{i}\right)_{j \geq 2}\right\}$ generate market clearing in the $k$-economy implies that the allocations also clear the markets in the $e$-economy. To see this note that:

$$
\begin{gathered}
\sum_{i \in I} c_{i}(\xi)=\sum_{i \in I} \widehat{c}_{i}(\xi)=F\left(z(\xi), \widehat{k}\left(\xi^{-}\right), \widehat{n}(\xi)\right)-\widehat{k}(\xi)+\sum_{j \geq 2} \widehat{d}^{j}(\xi) \widehat{A}^{j}=\widehat{w}_{c}(\xi)=w_{c}(\xi) \\
\sum_{j \geq 2} a_{i}^{j}(\xi)=\sum_{i \in I} \widehat{a}_{i}^{j}(\xi)=\widehat{A}^{j}=A^{j} \text { for } j \geq 2 \\
\sum_{i \in I} a_{i}^{1}(\xi)=\sum_{i \in I} \frac{\widehat{k}_{i}(\xi)}{\widehat{k}(\xi)}=1=A^{1}
\end{gathered}
$$

This establishes the result. 


\section{REFERENCES}

Aiyagari D. R. (1994): Uninsured Idiosyncratic Risk and Aggregate Saving, The Quarterly Journal of Economics, 109 (3), 659-684.

Angeletos. G. M., (2007): Uninsured Idiosyncratic Investment Risk and Aggregate Saving, Review of Economic Dynamics 10 (1).

Angeletos. G. M. and Calvet L.(2006): Idiosyncratic Production Risk, Growth and the Business Cycle, NBER Working Paper 9764, Journal of Monetary Economics 53:6.

Angeletos. G. M. and Calvet L. (2005), "Incomplete Market Dynamics in a Neoclassical Growth Economy", Journal of Mathematical Economics (41), 407-438.

Bewley, T. F. (1986): Stationary Monetary Equilibrium with a Continuum of Independently Fluctuating Consumers, in Hildebrand, W. and A. Mas-Collel (eds.), Contributions of Mathematical Economics in Honor of Gerard Debreu, Amsterdam: North-Holland, 79-102.

Bewley, T. F. (1977): The Permanent Income Hypothesis: A Theoretical Formulation, Journal of Economic Theory, 16 (2), 252-292.

Carceles-Poveda E. (2007): Asset Prices and Business Cycles under Market Incompleteness, forthcoming in the Review of Economic Dynamics.

Carceles-Poveda E. and Coen-Pirani, D., (2008): Shareholders Unanimity with Incomplete Markets, International Economic Review, forthcoming.

DeMarzo, P.M. (1993): Majority Voting and Corporate Control: The Rule of the Dominant Shareholder, Review of Economic Studies, 60, 713-734.

DeMarzo, P.M. (1988): An Extension of the Modigliani-Miller Theorem to Stochastic Economies with Incomplete Markets and Interdependent Securities, Journal of Economic Theory, 45, 353-369.

Diamond, P. A. (1967): The Role of a Stock Market in a General Equilibrium Model with Technological Uncertainty, American Economic Review, 57, 759-76.

Drèze, J. H. (1985): (Uncertainty and) the Firm in General Equilibrium Theory, Economic Journal, 95, 1-20.

Drèze, J. H. (1974): Investment under Private Ownership: Optimality, Equilibrium and Stability, in Allocation under Uncertainty: Equilibrium and Optimality, ed. by Drèze, J., NY, Macmillan.

Duffie, D., and W. Shaffer (1986b), Equilibrium and the Role of the Firm in Incomplete Markets, Unpublished manuscript.

Grossmann, S. J. and O. D. Hart (1979): A Theory of Competitive Equilibrium in Stock Market Economies, Econometrica, 47 (2).

Grossmann, S. J., and J., E. Stiglitz (1980): Stockholder Unanimity in Making Production and Financial Decisions, The Quarterly Journal of Economics, 94 (3), 543-566.

Grossmann, S. J., and J., E. Stiglitz (1977), On Value Maximization and Alternative Objectives for the Firm, The Journal of Finance, 32 (2), 389-402.

Hernandez, A., and M. Santos (1996), Competitive Equilibria for Infinite Horizon Economies, Journal of Economic Theory, 71, 102-130.

Krusell, P. and A. Smith (1998): Income and Wealth Heterogeneity in the Macroeconomy, Journal of Political Economy, 106 (5).

Krusell, P. and A. Smith (1997): Income and Wealth Heterogeneity, Portfolio Choice, and Equilibrium Asset Returns, Macroeconomic Dynamics, 1 (2), 387-422.

Leland, H., E. (1972): Theory of the Firm Facing Uncertain Demand, The American Economic Review, 279-291.

Levine, D.,.(1989): Infinite Horizon Equilibrium with Incomplete Markets, Journal of Mathematical Economics, 18, 357-376.

Levine, D., and W. Zame (1996): Debt Constraints and Equilibrium in Infinite Horizon Equilibrium with Incomplete Markets, Journal of Mathematical Economics, 26, 103-131. 
Magill, M. and M. Quinzii (1996): Theory of Incomplete Markets, The MIT Press.

Magill, M. and M. Quinzii (1994a): Incomplete Markets over an Infinite Horizon, Long Lived Securities and Speculative Bubbles, Journal of Mathematical Economics, 26, 133-170.

Magill, M. and M. Quinzii (1994b): Infinite Horizon Incomplete Markets, Econometrica, $62(4), 853-888$.

Magill, M. and M. Quinzii (2003): Nonshiftable capital, affine price expectations and convergence to the Goldern Rule, Journal of Mathematical Economics, 39, 239-272.

Radner, R. (1972a): New ideas in pure theory, Problems in the Theory of Markets under Uncertainty, American Economic Review, 454-460.

Sandmo, A. (1972): On the Theory of the Competitive Firm Under Price Uncertainty, The American Economic Review, 65-73.

Santos, M., and M. Woodford (1997): Rational Asset Pricing Bubbles, Econometrica, $65,(1), 19-57$.

Sondermann, D. (1974): Temporary Competitive Equilibrium Under Uncertainty,in Allocation under Uncertainty: Equilibrium and Optimality, ed. by Drèze, J., NY, Macmillan. 